\title{
DESIGN OF SMART HPMA COPOLYMER-BASED NANOMEDICINES
}

\author{
Jiyuan Yang ${ }^{1}$ and Jindřich Kopeček ${ }^{1,2,}{ }^{*}$
}

${ }^{1}$ Department of Pharmaceutics and Pharmaceutical Chemistry, ${ }^{2}$ Department of Bioengineering, University of Utah, Salt Lake City, Utah 84112, USA

"Corresponding author: Jindřich Kopeček, Center for Controlled Chemical Delivery, 20 S 2030 E, BPRB 205B, University of Utah, Salt Lake City, UT 84112-9452, USA. Phone: (801) 581-7211; Fax: (801) 581-7848.

E-mail address: jindrich.kopecek@utah.edu (J. Kopeček) 


\begin{abstract}
The state-of-the art in water-soluble macromolecular therapeutics has been reviewed. First the design principles for polymer-drug conjugates are discussed followed by two recent developments in the field: a) The design, synthesis and properties of backbone degradable $N$ (2-hydroxypropyl)methacrylamide (HPMA) copolymer-drug conjugates. The enhanced intravascular half-life of such conjugates creates a concentration gradient (blood vs. tumor) for an extended time interval resulting in increased solid tumor accumulation by enhanced permeability and retention (EPR) effect with concomitant increase in efficacy. b) Drug-free macromolecular therapeutics is a new paradigm in macromolecular therapeutics. Apoptosis in malignant cell is induced by crosslinking of cell surface non-internalizing receptors. Crosslinking of receptors is mediated by the biorecognition of two nanoconjugates containing high-fidelity complementary motifs (peptides or oligonucleotides). Results for the treatment of B cell lymphomas in animal models and patient cells demonstrate the high translational potential of this aproach.
\end{abstract}

Key words: Degradable polymeric carriers; drug-free macromolecular therapeutics; HPMA; oligonucleotides; coiled-coil peptides; self-assembly.

\title{
Contents
}

1. Introduction and historical background

2. Design principles for water-soluble polymer-drug conjugates

2.1 Polymer carriers: synthetic vs. natural

2.1.1 Impact of molecular weight of the carrier on fate and efficiency

2.1.2 Impact of structural factors on the fate of polymer carriers

2.1.3 Multifunctional issues

2.1.4 Architecture

2.2 Drug attachment and conjugate stability

2.2.1 Enzymatically cleavable spacers

2.2.2 Hydrolytically cleavable spacers

2.2.3 Reducible spacers

2.2.4 Self-immolative spacers

2.3 Targeted conjugates

2.4 Highlights of polymer-drug conjugate properties

3. Need for new/improved designs

4. Backbone degradable long-circulating ( $2^{\text {nd }}$ generation) conjugates

4.1 Multiblock degradable polymeric carriers

4.2 Diblock degradable polymeric carriers

4.3 Comparison of $2^{\text {nd }}$ generation conjugates with original $\left(1^{\text {st }}\right.$ generation) conjugates

5. New paradigm: Drug-free macromolecular therapeutics

5.1 Rationale and origin

5.1.1 Non-Hodgkin's lymphoma and CD20

5.2 Coiled-coil peptide based design 
5.2.1 Evaluation of potential immunogenicity of CCE, CCK and their conjugates

5.3 Morpholino oligonucleotide based design

5.4 Advantages and general applicability of the new paradigm

6. Conclusions and future prospects

\section{Introduction and historical background}

Polymers have been used in medicine for many years. The first application dates back to the 1940s when cellophane tubing used in sausages was utilized by Kolff to design the first artificial kidney. The tube was wrapped around a slated wooden drum and revolved in a tank filled with dialyzing solution [1]. In the 50 s and 60 s poly(vinyl alcohol) sponges (Ivalon) were used as breast implants [2]. Silicones have been used in several applications (tubings, shunts, urethra, joints) since the 1950s [3].

The first biomaterials rationally designed for human use were hydrogels. Lím synthesized hydrogels by crosslinking copolymerization of 2-hydroxyethylmethacylate (HEMA) [4] and Wichterle designed soft contact lenses using these materials [5]. They have been used in many applications in the clinic [6,7]. The rationale of design and the history of hydrogel discovery are reviewed in [6].

Sixty years ago, Jatzkewitz conjugated mescaline (drug) to polyvinylpyrrolidone (PVP) via a dipeptide spacer [8]. Ushakov's group in Leningrad (now St. Petersburg) conjugated numerous antibiotics to PVP and evaluated biological properties of the conjugates [9-11]. Mathé et al. was first to bind a drug to immunoglobulin [12]. De Duve discovered that numerous intracellular enzymes localize in the lysosomes (Nobel Prize 1974) and the lysosomotropism of macromolecules [13]. In 1975 Ringsdorf first clearly presented the concept of the use of polymers as targetable drug carriers [14]. The early results on polymer-drug conjugates are reviewed in ref. [15]. Another important use of polymers in therapeutics is protein modification. Davies and coworkers in the 1970s modified proteins with poly(ethylene glycol) to improve their intravascular half-life, immunogenicity, and stability [16]. The impact of the polymer structure on the properties of modified vesicular carriers was recently investigated [17].

New ideas on controlling the pharmacokinetics, pharmacodynamics, non-specific toxicity, immunogenicity, biorecognition, and efficacy of drugs were generated. These new strategies, often called drug delivery systems, are based on interdisciplinary approaches that combine polymer science, pharmaceutics, bioconjugate chemistry, and molecular biology. The combination of drugs with macromolecules created a new class of preparations macromolecular therapeutics. Drug delivery systems based on water-soluble polymeric carriers, micelle-forming block copolymers, nanospheres, microspheres, liposomes, dendrimers, and hydrogels are examples of this strategy. Hoffman's review provides an excellent perspective on a new paradigm in drug delivery, the design, synthesis and evaluation of drug-free macromolecular therapeutics. the historical development of drug delivery systems [18].

This review summarizes the design principles of water-soluble polymer-drug conjugates and highlights the advantages of polymer therapeutics when compared to low molecular weight drugs. After briefly mentioning the differences in conjugates' therapeutic activity in animal models vs. human clinical trials, two new designs [19] that have the potential to overcome the limitations and speed up the translation into clinics are discussed: a) $2^{\text {nd }}$ generation high molecular weight backbone degradable HPMA copolymer-drug conjugates synthesized by the 
combination of RAFT polymerization and chain extension via click reactions; and b) a new paradigm in drug delivery, the design, synthesis and evaluation of drug-free macromolecular therapeutics. This design is free of toxins and immune activation; apoptosis is initiated by crosslinking of receptors mediated by biorecognition of complementary motifs at cell surface.

\section{Design principles for water-soluble polymer-drug conjugates}

\subsection{Polymer carriers: synthetic vs. natural}

Polymers used as drug carriers must be well characterized; their structure should provide drug attachment/release sites for the incorporation of drugs. The carrier and all metabolic products should be nontoxic and nonantigenic. Likewise, the carriers should display the ability to be directed to predetermined cell types, and, they should be biodegradable or eliminated from the organism after fulfilling their function [20].

Macromolecules as drug carriers may be divided into naturally occurring and synthetic types. Frequently, it is assumed that polymeric drug carriers derived from natural products (polysaccharides, poly(amino acids), proteins) break down in the organism into small, easily eliminated fragments. However, the substitution of natural macromolecules with covalently linked drug molecules generally hampers the host's ability to effectively enzymatically degrade the polymeric carrier, because enzymes that cleave peptide or saccharide bonds have considerably large active sites that accommodate several amino acid or saccharide "monomer" units. Substitution along the macromolecular backbone renders the formation of the enzymesubstrate complex energetically less favorable. Therefore, drug substitution of a polymeric carrier, such as poly(amino acids) [21] or polysaccharides [22], may result in the inability of a naturally occurring, normally biodegradable macromolecule, to be degraded into small fragments able to cross the lysosomal membrane [23]. The larger fragments may accumulate in the lysosomes and increase the osmotic pressure with a potentially negative impact on biocompatibility.

Synthetic macromolecules can be tailor-made to have properties matching the biological situation [24]. However, to enhance elimination via glomerular filtration, the entire molecular weight distribution must be under the renal threshold - about $50 \mathrm{kDa}$ for neutral hydrophilic random coils. Further, to prevent the nonspecific reuptake of the macromolecule after being released into the bloodstream following cell death, its structure must be designed in such a way that internalization occurs by fluid-phase pinocytosis. The absence of nonspecific interactions with plasma membranes will minimize the accumulation of the carrier in nontargeted cells and thus increase the biocompatibility of the carrier.

\subsubsection{Impact of molecular weight of the carrier on fate and efficiency}

Molecular weight has an important impact on the in vivo fate of soluble polymers. The higher the molecular weight, the longer the intravascular half-life and the slower the elimination of polymers from the organism as shown in the fate of polyHPMA [25-31], polyvinylpyrrolidone [32], dextran and pullulan [33], and other structures (reviewed in [34,35]).

Kopeček and coworkers demonstrated the impact of the molecular weight of HPMA copolymerdoxorubicin (DOX) conjugates on solid tumor treatment. To verify the hypothesis that therapeutic efficacy of conjugates will be molecular weight dependent, they designed and synthesized branched, water-soluble HPMA copolymer-DOX conjugates containing lysosomally degradable oligopeptide sequences as crosslinks and side-chains terminated in DOX [30]. Four 
conjugates with $\mathrm{Mw}$ of $22,160,895$, and $1230 \mathrm{kDa}$ were prepared. Their biodistribution and treatment efficacy were evaluated in nu/nu mice bearing s.c. human ovarian OVCAR-3 carcinoma xenografts [31]. The half-life of HPMA copolymer - DOX conjugate (Mw $=1230 \mathrm{kDa})$ in blood was up to 28 times longer, and the elimination rate from the tumor was 25 times slower than that of free DOX. The results clearly demonstrated that $\mathrm{Mw}$ of conjugates has a significant effect on solid tumor treatment. The higher the molecular weight of the HPMA copolymer - DOX conjugates, the higher the tumor accumulation with concomitant increase in therapeutic efficacy [31].

\subsubsection{Impact of structural factors on the fate of polymer carriers}

Lammers et al. [36] evaluated the effect of physicochemical modification on the biodistribution and tumor accumulation of HPMA copolymers. Similar to other authors, they observed that increasing the molecular weight of HPMA copolymers resulted in prolonged circulation times and enhanced tumor concentration. Interestingly, they found that modification of the structure with carboxyl and hydrazide groups, or attachment of oligopeptide spacers terminated in drug decreased the intravascular half-life; consequently, lower levels of polymer were found in tumor and all organs except kidney. Importantly, tumor to tissue ratio did not change, indicating that functionalization did not affect the targetability of the conjugates [36].

Macromolecular therapeutics cannot cross the phospholipid bilayer by diffusion; they enter cells by endocytic pathways [37]. Most common classification schemes of endocytosis are based on protein machinery that facilitates the process, such as clathrin-mediated endocytosis, and clathrin independent endocytosis [38-41]. Clathrin independent endocytosis is further categorized as caveolae-mediated endocytosis and clathrin- and caveolin-independent endocytosis $[38,40]$ or dynamin dependent and dynamin independent endocytosis $[39,40]$. In addition, macropinocytosis is a distinct pathway of pinocytosis [42]. The relationship between the detailed structure of the polymer-drug conjugate and its mechanism of internalization is important information, which provides feedback for the optimization of the conjugate structure.

Recently, research has been focusing on the identification of different routes of cell entry with the aim to deliver drugs into subcellular compartments different from lysosomes. Since the activity of many drugs depends on their subcellular location, manipulation of the subcellular fate of macromolecular therapeutics may result in more effective conjugates. Approaches that seem to be effective are nuclear delivery of drugs mediated by steroid hormone receptors that shuttle between the cytoplasm and the nucleus [43] and mitochondrial targeting mediated by delocalized hydrophobic cations [44-47]. Of particular interest, the experiments of Murphy et al. used terminally functionalized triphenylphosphonium (TPP) to target peptide nucleic acids (PNA) into the mitochondria of isolated organelles and whole intact cells in vitro [46,47]. Attachment of TPP to HPMA copolymer resulted in enhanced mitochondrial localization following microinjection and incubation experiments with ovarian carcinoma cells [44,45]. Similar concept (attachment of TPP) was used for dendrimers [48,49], liposomes [50], gold nanoparticles [51] and blended biodegradable nanoparticles based on glycolic acid, lactic acid, and polyethylene glycol [52].

Nuclear entry of macromolecules. Macromolecules (without subcellular targeting moieties) are typically excluded from entering membrane-limited organelles, with the exception of nucleus whose membrane possesses channels that allow the passive uptake of intermediate-sized macromolecules. The NPC (nuclear pore complex) of the nuclear envelope is composed of about 30 different nucleoporin proteins and is the conduit for both nuclear import and export of macromolecules, such as proteins and nucleic acids. In active transport, cargo as large as 40 $\mathrm{nm}$ possessing NLS (nuclear localization sequence) or NES (nuclear export sequence) 
signaling peptides are guided through the channel after binding to nuclear transport receptor proteins [53]. For smaller macromolecules below $10 \mathrm{~nm}$, however, NPCs have been shown to act as non-specific pores that allow exchange between the nucleus and cytoplasm by diffusion [54]. As a conduit for non-biological macromolecules, the NPCs have been shown to transmit PEG-coated gold colloid particles 4-7 nm in diameter [55]. The basic physico-chemical properties that determine the distribution and fate of synthetic macromolecules in living cells were characterized using fluorescently-labeled HPMA copolymers [56]. Twelve different classes of water-soluble copolymers were created by incorporating eight different functionalized comonomers. These comonomers possessed functional groups with positive or negative charges, or contained short hydrophobic peptides (Figure 1). The copolymers were fractionated to create 10 fractions of narrow polydispersity with molecular weights ranging from 10 to 200 $\mathrm{kDa}$. The intracellular distributions were characterized for copolymer solutions microinjected into the cytoplasm of cultured MDAH2774 ovarian carcinoma cells. Even the highest molecular weight HPMA copolymers were shown to quickly and evenly diffuse throughout the cytoplasm and remain excluded from membrane-bound organelles, regardless of composition. The exceptions were the strongly cationic copolymers, which demonstrated a pronounced localization to microtubules. For all copolymers, nuclear entry was consistent with passive transport through the nuclear pore complex (NPC). Nuclear uptake was shown to be largely dictated by the molecular weight of the copolymers, however, detailed kinetic analyses showed that nuclear import rates were moderately, but significantly, affected by differences in comonomer composition. HPMA copolymers containing amide-terminated phenylalanineglycine (FG) sequences, analogous to those found in the NPC channel protein, demonstrated a potential to regulate import to the nuclear compartment. Kinetic analyses showed that $15 \mathrm{kDa}$ copolymers containing GGFG, but not those containing GGLFG, peptide pendant groups altered the size-exclusion characteristics of NPC-mediated nuclear import [56]. One possible explanation is that the GGFG moieties were able to weakly bind to FG-domain crosslinks in a way that altered the dynamics of a putative nucleoporin hydrogel structure, whereas GGLFG peptides would be expected to bind more strongly and not allow a rapid transfer of crosslinks in the hydrogel-like structure of the nucleopore proteins [57].

The same set of polymers was used to study the relationship between the polymer structure and uptake and subcellular trafficking into cultured C4-2 prostate cancer cells [37]. The copolymer charge was the predominant physicochemical feature in terms of cellular uptake. Fast and efficient uptake occurred in positively charged copolymers due to non-specific adsorptive endocytosis, whereas slow uptake of negatively charged copolymers was observed (Figure 1). The uptake of copolymers was also molecular weight dependent. The copolymers were internalized into the cells through multiple endocytic pathways: positively charged copolymers robustly engaged clathrin-mediated endocytosis, macropinocytosis and dynamin-dependent endocytosis, while weakly negatively charged copolymers weakly employed these pathways; strongly negatively charged copolymers only mobilized macropinocytosis. HPMA copolymer possessing $4 \mathrm{~mol} \%$ of moderately hydrophobic functional groups did not show preferential uptake. All copolymers ultimately localized in late endosomes/lysosomes via early endosomes; with varying kinetics among the copolymers [37].

Conformation and aggregation. Anticancer drugs are usually hydrophobic and their binding to hydrophilic water-soluble polymers will impact the solution properties of the polymer-drug conjugates. As a result, drug conjugates may associate intramolecularly and intermolecularly, affecting the conformation of single chains and yielding formation of aggregates, respectively [58-60]. This effect gains importance in multifunctional conjugates as described below. 

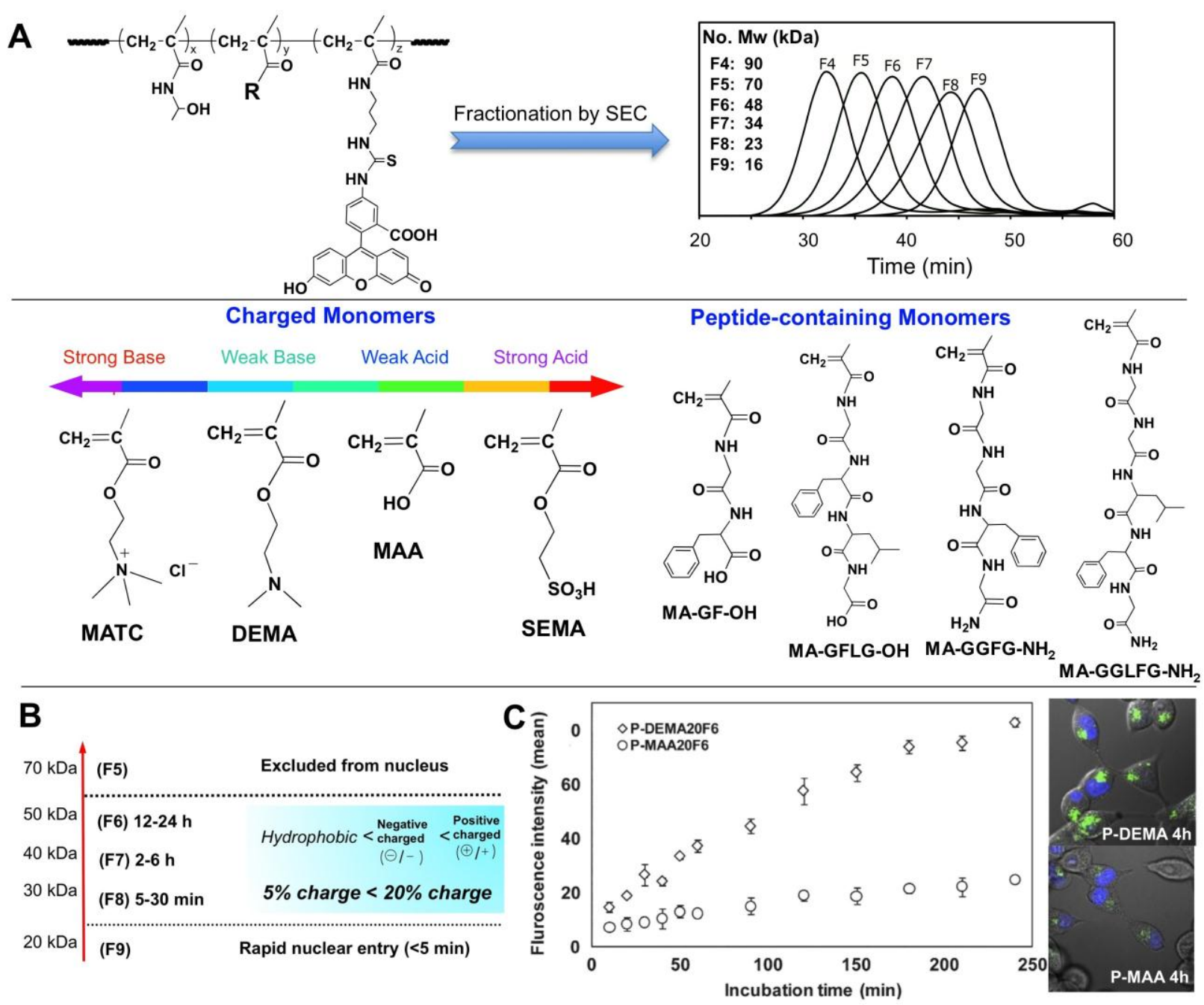

Figure 1. A) Structure of monomers and polymers [37,56]; B) Impact of $M w$ and structural factors on transport of macromolecules from the cytoplasm into the nucleus [56]; C) Internalization of positively and negatively charged macromolecules into prostate cancer cells [37].

\subsubsection{Multifunctional issues}

Multifunctional polymeric drug carriers containing several components, such as targeting modules, drug releasing modules, and endosome disruptive modules, have showed the potential to perform multiple functions within a single structure [61]. Ideally, each component within the delivery system should function independently, without affecting the functionality of the other components. However, the physical and biological properties of multifunctional conjugates exert some influence on the other components [59,62-64]. Therefore, awareness of the complexities caused by the introduction of each component is needed to design multicomponent drug carriers [65]. For example, higher amounts of the hydrophobic drug prostaglandin $E_{1}$ bound to polyHPMA macromolecules resulted in a lower rate of drug release [62]. Ding et al. studied the self-association of HPMA copolymers containing an amphipathic CD21-binding heptapeptide (YILIHRN) using fluorescence resonance energy transfer (FRET), light scattering, and size exclusion chromatography (SEC) [66]. The process of association, largely the result of intra-polymer hydrophobic interactions, resulted in a unimolecular micelle structure. The degree of self-association increased with increased heptapeptide content. The self-association of HPMA copolymer-peptide conjugate was disrupted by the incorporation of acrylic acid comonomers into the HPMA copolymer backbone; the ionization of $\mathrm{COOH}$ groups 
along the polymer chains induced a conformational change into an extended conformation. On the other hand the formation of unimolecular micelles (in the absence of ionizable comonomer) resulted in decreased enzyme biorecognizability and accessibility of oligopeptide side-chains (GFLG) by papain. A better understanding of the relationship between the self-association of polymer conjugates [67] and biological significance is a prerequisite for the rational design of polymeric drug delivery systems.

\subsubsection{Architecture}

Polymer architecture has an important impact on the activity of the conjugates. Ulbrich's group studied in detail the relationship between the architecture of HPMA copolymers - linear conjugates, branched conjugates, grafted conjugates, self-assembled micellar conjugates, and grafted dendritic star conjugates - and their activity [reviewed in 68]. Szoka and Fréchet performed careful studies on the impact of molecular architecture (hydrodynamic volume, conformation, flexibility, and branching) on the fate of polymers in the organism. They concluded that molecular architecture has a serious impact on the elimination of the carrier via glomerular filtration, but a much smaller impact on the extravasation of the polymer into the tumor [reviewed in 69].

An interesting design is the combination of dendrimers with water-soluble polymer-drug conjugates. PAMAM dendrimers were modified with semitelechelic (ST) HPMA copolymer DOX conjugates [70,71]. Ulbrich, Etrych and coworkers were very active in this area. They attached the ST HPMA copolymer-drug conjugates to PAMAM dendrimers via $\mathrm{pH}$-sensitive hydrazone bonds to render the constructs biodegradable [72]. Additionally, they attached ST drug conjugates directly to immunoglobulin molecules via hydrazone [73] or disulfide linkages [74].

\subsection{Drug attachment and conjugate stability}

Macromolecules are lysosomotropic [13]. Due to limited permeability of lysosomal membrane [23], drugs have to be cleaved from the polymeric carrier in the lysosomal compartment either by enzymatically catalyzed hydrolysis or by pure hydrolysis at lower $\mathrm{pH}$. The drug is usually bound to the polymeric carrier via spacers with different structures (see below). Drug incorporation into a polymer conjugate can be achieved by copolymerization with a polymerizable drug derivative or by polymeranalogous reaction, i.e., attaching the drug to a preformed polymer carrier $[75,76]$. If avoidance of the lysosomal compartment is needed due to instability of the drug (e.g., DNA based) destabilization of the prelysosomal (endosomal) membrane combined with the reduction of disulfide bonds between drug and carrier is a suitable design $[77,78]$.

\subsubsection{Enzymatically cleavable spacers}

To ensure drugs released from the carriers inside lysosomes and translocated into the cytoplasm. the structure of the spacer has to provide stability of the bond between the drug and carrier in the blood stream [79] and interstitial space and match the specificity of lysosomal enzymes [80]. Based on detailed degradation studies of oligopeptide sequences attached to HPMA copolymers [reviewed in 81,82] with model enzymes [83-86], in rats in vivo [87] and with lysosomal enzymes [88,89], the sequence GFLG, specific for cathepsin B, was identified [90]; it has been widely used in preclinical [91-95] and clinical settings [96-99]. Another widely used lysosomally degradable sequence is valine-citruline [100,101]. The employment of matrix metalloproteinase (MMP) enzymes in the design of drug delivery systems has been demonstrated [102]. Efficient conjugates have been synthesized using a combination of MMP-2 
cleavable bonds and tumor-homing and cell-penetrating peptide iRGD. These conjugates possess enhanced accumulation and penetration into tumors in a model system [93].

The design of enzymatically cleavable spacers is well covered in the literature so we shall avoid details here. We refer the reader to the following articles and references therein [80$90,103,104]$.

\subsubsection{Hydrolytically cleavable spacers}

Another design option is to use the $\mathrm{pH}$ difference between blood and lysosomes and bind the drug via pH-sensitive bonds [105,106], using hydrazo [107], cis-aconityl [108], or maleic [78] spacers. The area is well-reviewed in [105]. The effect of HPMA copolymer carrier modification with positively or negatively charged groups and hydrophobic substituents on the rate of release was recently evaluated [109]. The results revealed no change in the rate of DOX release when positively charged groups were introduced and $15-20 \%$ increase in release rate when carboxylic group containing comonomers were introduced. Introduction of oleyl group led to aggregation and decrease in the rate of release [109].

\subsubsection{Reducible spacers}

The difference in intracellular oxidoreductive conditions compared to the outside of the cell presents a unique opportunity that can be exploited for site-specific delivery. High concentrations of cystine $(40 \mu \mathrm{M})$ and correspondingly low concentrations of reducing agents, cysteine $(9.7 \mu \mathrm{M})$ and reduced glutathione $(2.8 \mu \mathrm{M})$, produce an oxidative environment extracellularly [110]. On the other hand, the cytosol is reducing due to the high intracellular concentration of reduced glutathione $(5 \mathrm{mM})$ as compared to oxidized glutathione, which may be present at a 100-fold lower concentration [111]. This highly reductive cytosolic condition is maintained by the action of glutathione reductase and NADPH [112,113]. In the endocytotic pathway, active accumulation of cysteine in lysosomes, due to cysteine transporters [114,115], may facilitate disulfide bond reduction. This may be enhanced by the action of reducing enzymes, such as Gamma-Interferon Inducible Lysosomal Thiol Reductase (GILT). This enzyme was the first reductive enzyme found in the lysosomes of antigen presenting cells and is optimally active at a pH less than neutral. The activity of GILT may require the presence of a reducing agent such as cysteine to maintain activity [116].

Disulfide bonds have been incorporated in the synthesis of cleavable delivery systems for DNA, RNA, and siRNA [117-121], antisense oligonucleotides [122], peptides [123], toxins [124] and anticancer drugs [125-127]. An interesting design is the dynamic conjugates that combine endosomolytic function with siRNA reductive release $[77,128,129]$. Such multifunctional conjugates contain comonomers with amino groups protected by $\mathrm{pH}$-sensitive bonds, hydrophobic comonomers, and cargo (siRNA) bound via disulfide bonds. In the endosomes the amino group protection (usually a semitelechelic hydrophilic polymer) is cleaved off, the combination of electrostatic (via amino groups) and hydrophobic interaction destabilizes the endosomal membrane. The reductive environment then reduces the disulfide bonds and releases siRNA into the cytoplasm.

\subsubsection{Self-immolative spacers}

Katzellenbogen and coworkers introduced a new type of spacer [130] where the biologically active molecule (drug) is bound to the carrier via spacer (S) and a linker (L). Following enzymatic cleavage of the bond between $S$ and $L$, a spontaneous rearrangement of the $L$ structure results in the release of the free, unmodified drug (Figure 2). Typical linker groups employ benzyl eliminations for the release of drugs - 1,4- or 1,6-elimination. The aromatic structure contains a hydroxyl, amino or thiol group. When covalently bound these groups are 
stable; however, activation by e.g. enzymatic cleavage produces a nucleophilic compound that initiates self-immolation releasing the unmodified drug [100,131-133].

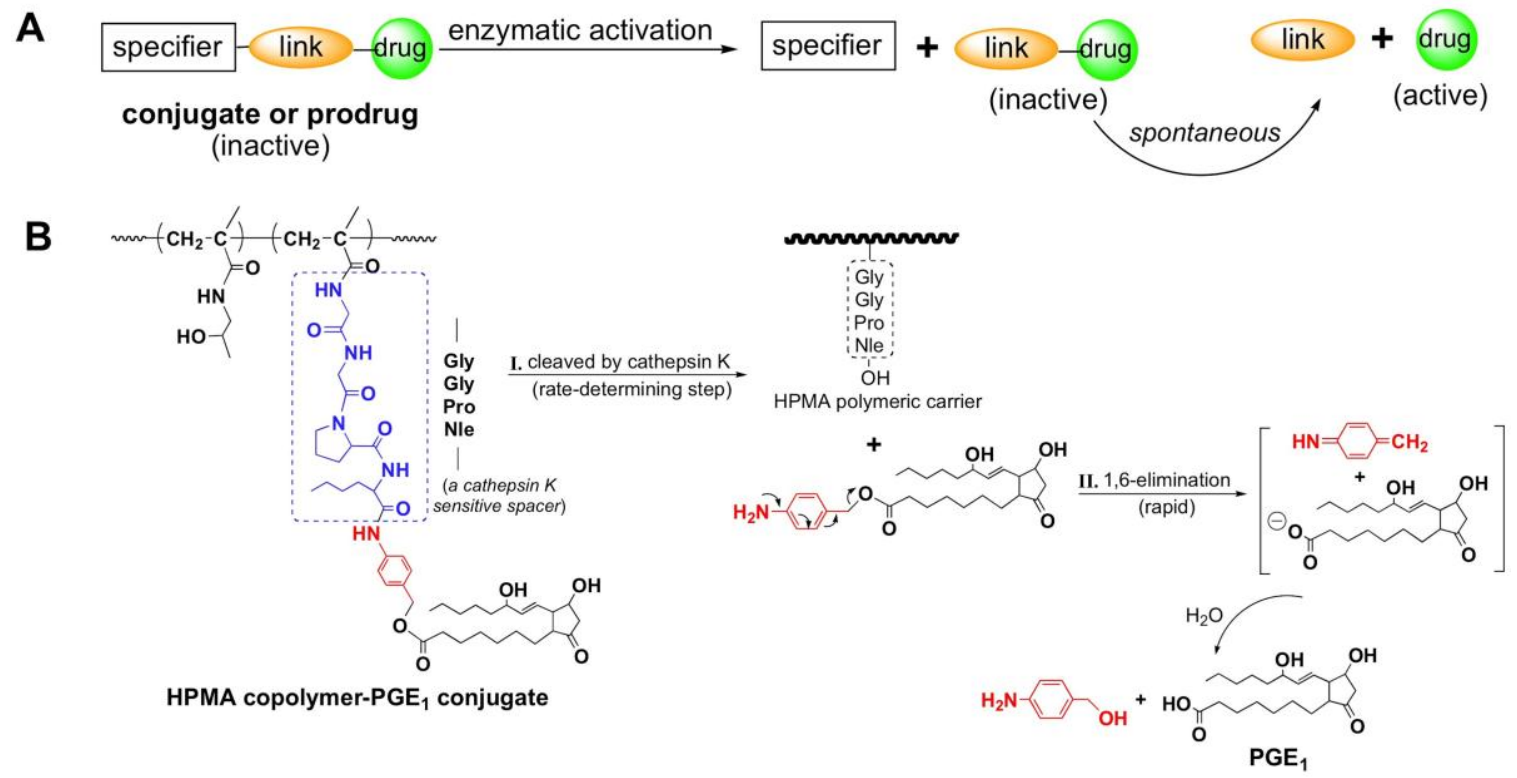

Figure 2. Self-immolative spacers. a) Principle of design [130]; b) Scheme of release of unmodified prostaglandin ( $\mathrm{PGE}_{1}$ ) from HPMA copolymer-PGE 1 conjugates by a two-step process - rate controlling enzymatic cleavage followed by fast 1,6-elimination [62].

Self-immolative spacers have been used in the design of drug delivery systems, prodrugs, sensors for chemicals or enzymes, and in material science [131]; several examples follow. Dubowchik et al. developed immunoconjugates of BR96 antibody (Ab) with doxorubicin (DOX) containing dipeptide spacers (Val-Lys, Val-citrulin) cleavable in the lysosomal compartment, especially by cathepsin B [104]. To avoid steric crowding at the position P1 (S-P nomenclature according to Schechter and Berger [134]) and to achieve cleavage a p-aminobenzylcarbonyl (PABC) 1,6-elimination group was inserted between the Ab and Val-Cit-DOX.

Elongated spacers, where the enzymatically cleavable bond is separated from the drug by a self-eliminating 4-aminobenzylalcohol structure group, have been used for the design of oral drug delivery systems based on HPMA copolymer - 9-aminocamptothecin conjugates $[135,136]$ and for binding prostaglandin to HPMA copolymer via a cathepsin $\mathrm{K}$ sensitive tetrapeptide (GGPNle) [62]. Putnam et al. synthesized oligopeptide spacers terminated in $\alpha$-substituted glycine derivative of 5 -fluorouracil (5-FU). Following enzymatically catalyzed release of 5-FU substituted glycine a spontaneous decomposition yielded 5-FU and a glyoxylate [137]. Shabat et al. used the self-immolative concept for the design of degradable materials (e.g. dendrimers) [138] and demonstrating that one trigger reaction may result in the release of numerous drug molecules at once [139].

\subsection{Targeted conjugates}

Numerous compounds complementary to target receptors can be used as targeting moieties, such as antibodies [74,140-143], antibody fragments [144,145], saccharides [146-148], lectins [149,150], peptides [61,66,151-156], aptamers [157], small molecule ligands [92], etc. The impact of a targeting moiety on the biodistribution and efficacy of the conjugate will depend on the type of tumor and structure of the conjugate [158,159]. As discussed in more detail in ref. 
[158] targeting for solid tumors may not be needed due to the enhanced permeability and retention (EPR) effect and beneficial manipulation of molecular weight of conjugates. In contrast, for the treatment of blood cancers, such as non-Hodgkin's lymphoma, targeting is beneficial.

Cancer cells are present in various differentiation statuses, such as cancer stem cells (CSC) and differentiated cells [160]. Only the CSCs, with the ability to self-renew and differentiate, have the tumorigenic potential and are able to generate phenotypically heterogeneous tumor cell populations that resemble the original organizations of the parent tumor. The hierarchical CSC theory suggests that the unsuccessful treatment of cancers is largely due to the failure of conventional cytotoxic anti-cancer therapies to eliminate CSCs. Therefore, targeting CSCs in combination with traditional anticancer therapeutics represents a promising strategy to improve cancer patient survival [161-163].

\subsection{Highlights of polymer-drug conjugate properties}

Here we shall briefly discuss the advantages of polymer-bound drugs when compared to low molecular weight (unbound) drugs:

Enhanced stability of drugs. Binding of a chemically labile drug to a polymer carrier results in its stabilization. For example, cytarabine (CYT) is the most active agent available for the treatment of acute myeloid leukemia (AML). However, the potency of CYT is limited by its low stability after intravenous administration due to the metabolism into the inactive and more soluble form by cytidine deaminase. When bound to HPMA copolymer via GFLG side chains improved human plasma stability was achieved. After $48 \mathrm{~h}$, all free drug disappeared, whereas there was still close to $50 \%$ of the polymer-bound drug present indicating advantage of conjugation of CYT to a polymer carrier [94].

Different mechanism of cell entry. It is well know that in contrast to low molecular weight compounds that can cross the plasma membrane by diffusion, macromolecules (and polymerdrug conjugates) enter cells by endocytosis with the ultimate location in the lysosomal compartment of the cell [37-42]. The rational design of polymer-drug conjugates is based on these phenomena [160].

Changed pharmacokinetics. Attaching drugs to polymer carriers results in enhanced intravascular half-life and changed biodistribution [164,165]. The pharmacokinetic parameters can be manipulated by the molecular weight and the structure and conformation of the polymer carrier [36,166].

Overcoming multidrug resistance. The fact that macromolecules' subcellular trafficking occurs in membrane limited organelles renders the drug-efflux pumps, present in multidrug resistant cells, less efficient [167]. Free (unbound) drug is recognized by the membrane transporter (e.g., Pglycoprotein) when trying to enter the cell [168]. In contrast, lysosomes are located in the perinuclear region and the drug released from the polymer carrier will enter cytoplasm in this region out of reach of the P-glycoprotein. This rationale was validated for HPMA copolymerDOX conjugates in vitro and in vivo [169-171].

Immunostimulatory effect. The long-term efforts to employ the immune system in the treatment of cancer [172] did not miss the drug delivery field. Říhová and coworkers realized the immunostimulatory potential of HPMA copolymer-drug conjugates more than 25 years ago. They have shown that HPMA copolymer-daunomycin conjugate was not myelotoxic, but 
stimulated bone marrow stem cells resulting in an increase in the number of colony-forming units in the spleen [173]. A following study [174] has demonstrated that HPMA copolymer bound anticancer drugs, in contrast to unbound drugs, did not induce Fas ligand expression in cancer cells and thus did not trigger the death of antitumor effector cells. The proposed mechanism of the combined cytostatic and immunostimulatory activity postulates that first chemotherapy-sensitive tumor cells are killed, releasing tumor antigens. Then, the antitumor response will result in the elimination of chemotherapy-resistant cells $[175,176]$. The fact, that mice cured from EL4 T-cell lymphoma with HPMA copolymer-DOX conjugates survive retransplantation without further treatment supports the hypothesis [177].

\section{Need for new/improved designs}

The advantages of polymer-bound drugs, briefly described above, are numerous $[15,68,81,82,98,158,178-182]$. They have been tested in several clinical trials [183-186], but the translation of laboratory results into the clinics has been slow $[19,187]$. The research directions possessing a potential to enhance the speed of translation were discussed recently [19]. The polymer-drug conjugates in clinical trials demonstrated a decrease of adverse effects when compared to the administration of free (unbound) drug. However, the enhancement of the efficacy of treatment was lower than in animal models. This is most probably related to the ratio of tumor volume to body volume. In humans the ratio (of tumor volume to body volume) is much lower than in animal models and not enough conjugate extravasates into the solid tumor when a conjugate with a short intravascular half-life is used. To achieve an effective accumulation of the conjugate into the solid tumor a concentration gradient for an extended time is needed. The design of conjugates that can achieve this - backbone degradable carriers of anticancer drugs will be used as the first example.

Another direction how to move the field forward is to design new, previously unused approaches. We invented a new paradigm in drug delivery - "drug-free macromolecular therapeutics". This strategy is based on the induction of apoptosis by crosslinking of receptors mediated by the biorecognition of two nanoconjugates at the cell surface. Importantly, no low molecular weight drug is needed. This approach will be used as the example of new trend in macromolecular therapeutics research.

\section{Backbone degradable long-circulating (2 ${ }^{\text {nd }}$ generation) conjugates}

As mentioned above, molecular weight $(\mathrm{Mw})$ and molecular weight distribution are important factors in the design of effective macromolecular therapeutics. The higher the molecular weight of the polymer carrier, the higher the accumulation of the polymer-drug conjugate in the tumor tissue with concomitant increase in therapeutic efficacy [31,82]. However, the renal threshold limited the molecular weight of the first generation (non-degradable) polymeric carriers to below $50 \mathrm{kDa}$ [26]; this lowers the retention time of the conjugate in the circulation with simultaneous decrease in pharmaceutical efficiency. It is evident from previous research that for an efficient EPR effect a concentration gradient for an extended time is essential. Higher molecular weight drug carriers with a nondegradable backbone deposit and accumulate in various organs, impairing biocompatibility. Clearly, new designs are needed. To address the challenge, we designed backbone degradable HPMA copolymer carriers that possess a long circulating time while preserving biocompatibility. The new design of backbone degradable HPMA copolymer drug carrier is based on the state-of-the-art approaches - combination of controlled/living radical polymerization and click reactions [188-190]. The backbone degradable HPMA copolymer-drug 
conjugates provide long circulating water-soluble polymeric carriers that effectively accumulate in tumor tissue. They will be eliminated from the body after enzymatic cleavage of the oligopeptide segments in the backbone (producing polymer fragments below the renal threshold) and in side chains (releasing the drug). The synthesis procedures proposed are versatile; they provide a platform for the preparation of a large variation of polymer-drug conjugates with tailor-made properties, such as predetermined circulation time and composition.

\subsection{Multiblock degradable polymeric carriers}

Multiblock backbone degradable HPMA copolymers are prepared in two steps: first, a telechelic diblock copolymer is prepared by RAFT (reversible addition-fragmentation chain transfer) polymerization using a bifunctional CTA followed in the second step by chain extension using alkyne-azide [188,189] or thiol-ene [190] click reactions resulting in long circulating multiblock HPMA copolymer-drug conjugates. Finally, the product needs to be fractionated by size exclusion chromatography (SEC). Figure 3 shows an example of synthesis of multiblock HPMA copolymer-drug conjugates using Peptide2CTA. Following this approach, various multiblock conjugates containing anticancer drugs paclitaxel [191,192], gemcitabine [192], doxorubicin [193] have been synthesized and evaluated in vitro and in vivo.

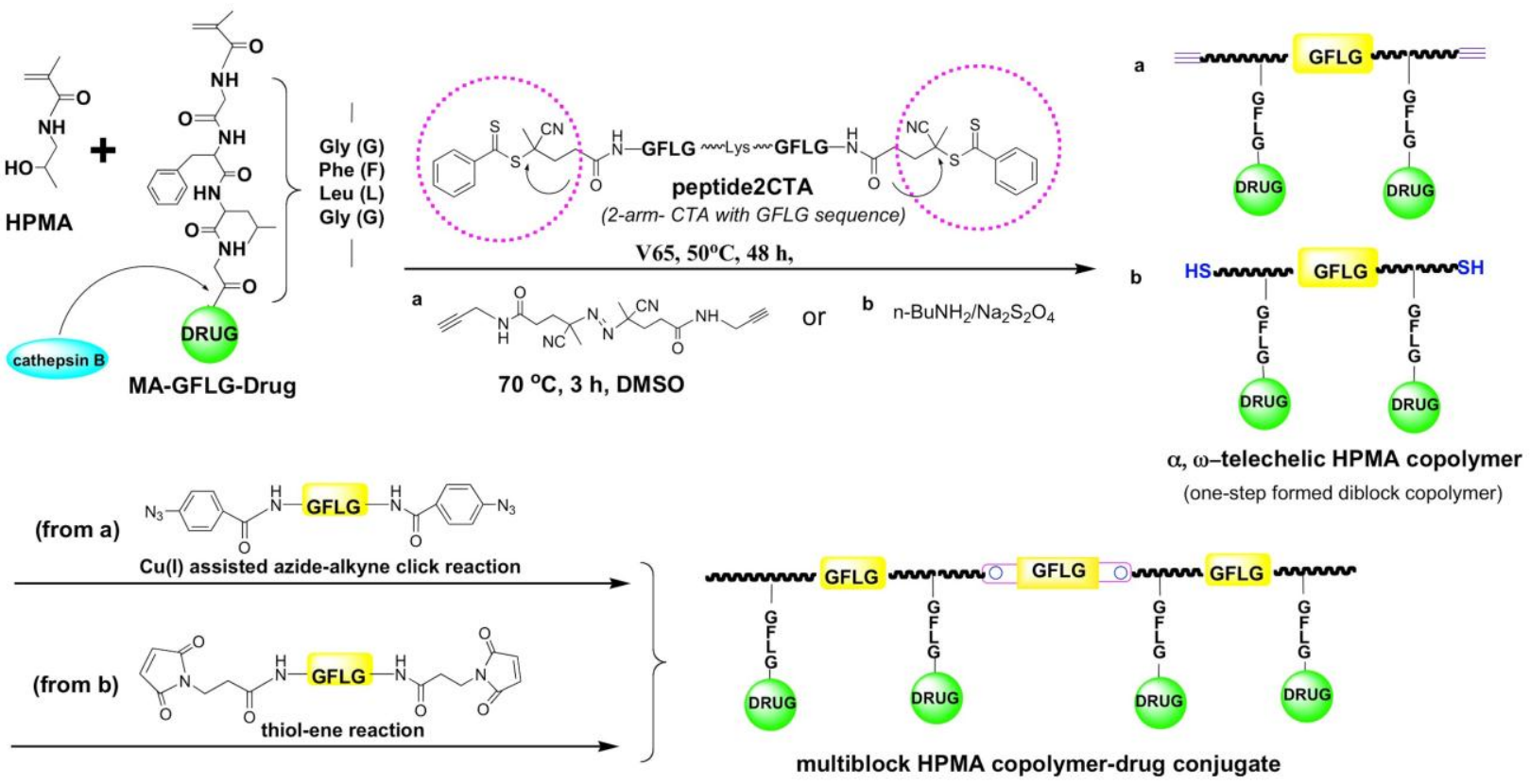

Figure 3. Synthesis of multiblock degradable HPMA copolymer-drug conjugates [190-193]

\subsection{Diblock degradable polymeric carriers}

Using an RAFT chain transfer agent (CTA) (Peptide2CTA) that contains an enzymatically degradable oligopeptide (GFLGKGLFG) flanked by two dithiobenzoate groups, the synthesis of degradable diblock copolymers of narrow polydispersity can be done in one step [190]. This feature makes the Peptide2CTA very attractive for scale-up of the synthetic procedures. During RAFT polymerization the monomers incorporate at both dithiobenzoate groups of the Peptide2CTA with identical efficiency. When the final polymer was incubated with papain, a thiol proteinase with similar specificity as lysosomal proteinases, the molecular weight decreased to half of the original value [190]. Degradable diblock copolymers extend the 
biocompatible molecular weight range to $100 \mathrm{kDa}$. The copolymers have a narrow distribution of molecular weights and the process is scalable.

\subsection{Comparison of $2^{\text {nd }}$ generation conjugates with original ( $1^{\text {st }}$ generation) conjugates}

The enhanced activity of $2^{\text {nd }}$ generation of conjugates when compared to $1^{\text {st }}$ generation conjugates (non-degradable, Mw below the renal threshold) has been proven in vivo. Longcirculating backbone degradable HPMA copolymer conjugates with doxorubicin [193], paclitaxel [191], gemcitabine [194] demonstrated higher efficacy in suppressing the growth of human ovarian carcinoma xenografts in nude mice than $1^{\text {st }}$ generation conjugates. Similarly, bonetargeted long-circulating conjugates containing prostaglandin $E_{1}$ had higher accumulation on bone tissue and greater indices of bone formation in an ovariectomized rat osteoporosis model when compared to $1^{\text {st }}$ generation conjugates [195].

Interestingly, in vivo experiments on animal models of ovarian cancer have proven that the diblock structure is sufficient to dramatically enhance efficacy when compared with the first generation conjugates $[166,193]$. Combination chemotherapy with $2^{\text {nd }}$ generation backbone degradable diblock HPMA copolymer-paclitaxel and HPMA copolymer-gemcitabine conjugates against A2780 human ovarian carcinoma xenografts was recently evaluated and results compared with $1^{\text {st }}$ generation conjugates and free drugs [166]. The $2^{\text {nd }}$ generation degradable high-Mw conjugates showed distinct advantages, such as favorable pharmacokinetics (3-5xhalflife when compared to the $1^{\text {st }}$ generation), dramatically enhanced inhibition of tumor growth (complete tumor regression) by paclitaxel and gemcitabine conjugates combination, and absence of adverse effects (Figure 4). In addition, multimodality imaging studies of dual-labeled model conjugates confirmed the efficacy of $2^{\text {nd }}$ generation conjugates by visualizing more than 5 times enhanced tumor accumulation, rapid conjugate internalization, and effective intracellular release of payload. Together, the results indicate that the $2^{\text {nd }}$ generation degradable HPMA copolymer carrier can provide an ideal platform for the delivery of a range of antitumor compounds, which makes it one of the most attractive candidates for potential clinical application [166]. 

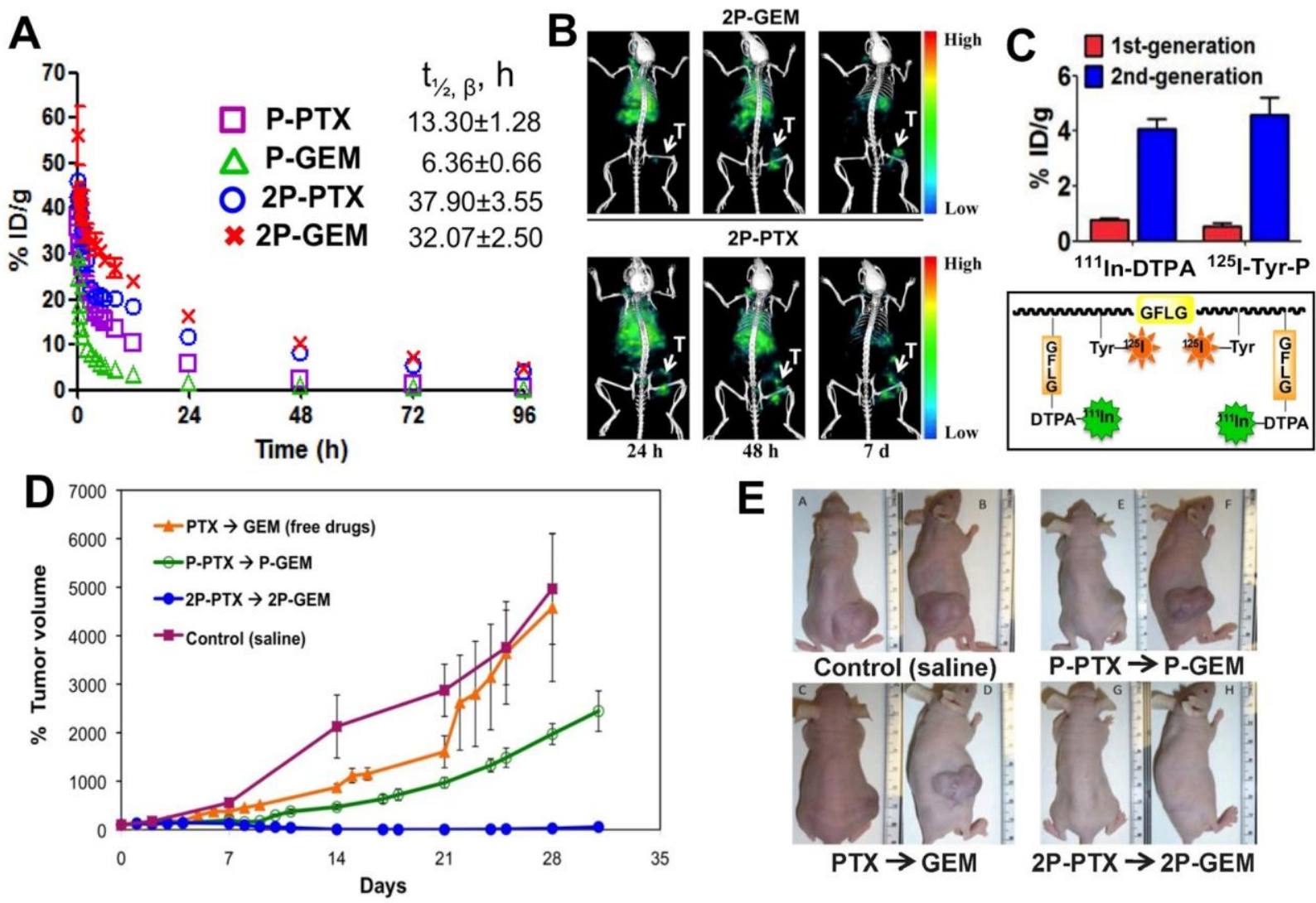

Figure 4. Combination treatment of $2^{\text {nd }}$ generation backbone degradable diblock conjugates showed improved therapeutic efficacy in A2780 human ovarian carcinoma xenografts. (A) Blood activity-time profiles of ${ }^{125}$-labeled conjugates in mice. The data represent the mean radioactivity expressed as a percentage of the injected dose per gram of blood from mice $(n=5)$. (B) SPECT/CT images of mice bearing subcutaneous A2780 human ovarian carcinoma in right flank after intravenous injection of ${ }^{125}$ labeled diblock conjugates (2P-PTX, 2P-GEM). The representative images were acquired $24 \mathrm{~h}, 48 \mathrm{~h}$, and $7 \mathrm{~d}$ after administration of conjugates. T, tumor. (C) Tumor uptake of dual-labeled conjugates (111/n-DTPA as model drug and ${ }^{125}$-Tyr-P as polymer carrier) in mice bearing subcutaneous A2780 tumor $48 \mathrm{~h}$ after injection of first- or second-generation conjugates. Data are plotted as percentage of injected dose per gram of tissue (\% ID/g). All of the data are expressed as mean \pm SD $(n=4-5)$. (D) A2780 tumor growth in mice treated with different formulation combinations $(n=5) .{ }^{*} p<0.01$. Female nude mice received one dose of PTX or HPMA copolymer-PTX conjugate $(20 \mathrm{mg} / \mathrm{kg}$ PTX equivalent) on day 0 and 3 doses of GEM or HPMA copolymer-GEM conjugate (5 mg/kg GEM equivalent) on days 1,7 , and 14 . Note: in the orange (2P-PTX $\rightarrow 2 \mathrm{P}-\mathrm{GEM}$ ) line the error bars are hidden within the experimental points. (E) Photographs of A2780 tumors after treatment with different combinations. Mw of conjugates: P-GEM - 40 kDa; 2P-GEM - 110 kDa; P-PTX - 50 kDa; 2P-PTX -115 kDa. Adapted from ref. [166].

\section{New paradigm: Drug-free macromolecular therapeutics}

\subsection{Rationale and origin}

The idea to design drug free therapeutics was based on the known mechanism of apoptosis induction in B cells via crosslinking of the CD20 receptor [196] and our studies on selfassembling hybrid graft HPMA copolymers [197]. It has been known that crosslinking of (noninternalizing) CD20 receptors initiates apoptosis in B cells. At the same time we found that two 
HPMA copolymers grafted with complementary coiled-coil forming peptides self-assemble into hydrogels $[197,198]$. The self-assembly was mediated by the biorecognition of the peptide grafts [199]. Thus we hypothesized that if we can crosslink graft copolymers with concomitant formation of hydrogels, we could crosslink cell surface (non-internalizing) CD20 receptors with simultaneous apoptosis induction. Indeed, we succeeded and the activity of this system both in vitro and in vivo was far better than we expected [reviewed in 200].

\subsubsection{Non-Hodgkin's lymphoma and CD20}

Non-Hodgkin's lymphoma (NHL) originates about $85 \%$ from B cells and the remaining $15 \%$ are mostly T-cell related. The approval of Rituximab, an anti-CD20 antibody revolutionized the field. However, large populations of patients exist that do not respond or develop resistance to therapy. CD20 is a 35-37 kDa integral membrane protein highly expressed on more than $95 \%$ of B-cell lymphomas [201]. Free CD20 antigen is not present in serum, and when bound to ligand (antibodies), it has a very low intracellular internalization rate [202]; CD20 is often considered a non-internalizing receptor. It functions as a store-operated calcium channel and a cell cycle regulator [203]. It is one of the most reliable biomarkers of B-lymphocytes, thus providing an ideal target for treatment of B-cell NHL [204]. CD20 is also expressed on normal B-cells; however, it is not expressed on stem cells or progenitor cells and mature or activated plasma cells [205]. Therefore, the "B-cell depletion" therapeutic approach is considered safe; normal numbers of B-cells can be restored after treatment [206]. Apoptosis initiated by antiCD20 mAbs occurs by three cellular events: a) antibody-dependent cellular cytotoxicity (ADCC); b) complement-dependent cytotoxicity (CDC); and c) CD20-mediated apoptosis [207-209]. All of these mechanisms require immune effector cells to function [209]. The third mechanism (c) is initiated by crosslinking of bound antibodies by immunocompetent cells via the Fc fragment.

Direct crosslinking of CD20 receptors leads to apoptosis. Studies with synthetically crosslinked Rituximab have shown enhanced induction of apoptosis and tumor clearance when compared with Rituximab alone [210,211]. Multivalent Fab' fragment - HPMA copolymer conjugates induce apoptosis in Raji B cells via crosslinking of CD20 receptors [212-214]. Similarly, multivalent rituximab lipid nanoparticles [215] and nanoparticles self-assembled from fusion between a single chain antibody and a soluble protein polymer [216] induce apoptosis. However, such constructs are difficult to synthesize and they do not permit to use pretargeting strategies. Binary systems, described below are suitable for such strategies [217].

The apoptotic pathways provided a roadmap for the design of the new treatment paradigm. Avoiding the Fc fragment and using Fab' antibody fragment one could decorate cells with a moiety bound to the Fab' fragment. Then, the crosslinking of receptors could be achieved by using a graft copolymer containing several copies of a complementary structure. This would avoid crosslinking via immunocompetent cells, ADCC and CDC mechanisms, and side effects of therapy associated with the Fc fragments [218]. Drug-free macromolecular therapeutics trigger direct and specific apoptosis of B-cell lymphomas without the help of effector cells (Figure 5). This is achieved by the design of synthetic effectors that reproduce the function of immune effector cells. 


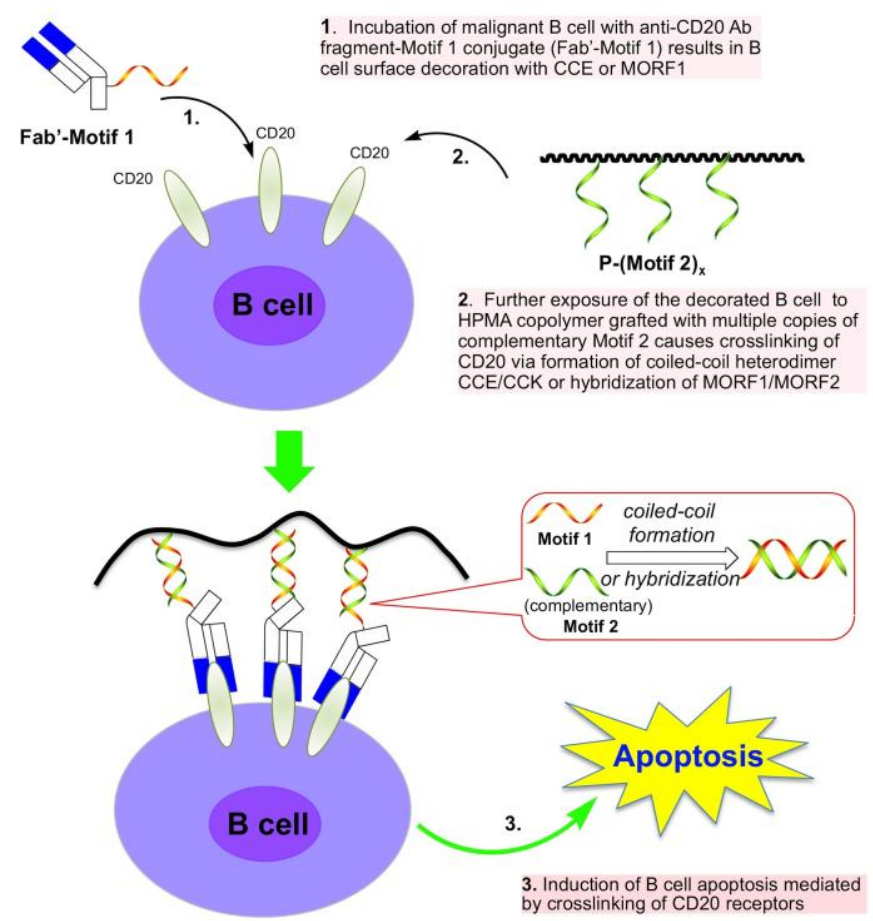

Figure 5. Drug-free macromolecular therapeutics. Cartoon of overall design and possible mechanism of treatment of $\mathrm{NHL}$ with conjugates of antiparallel coiled-coil forming peptides, CCE and CCK or morpholino oligonucleotides, MORF1 and MORF2. The induction of apoptosis in human Burkitt's NHL Raji $B$ cells was triggered by crosslinking of the surface CD20 antigen mediated by the biorecognition of antigen-antibody and complementary motifs [220,221,232,241].

\subsection{Coiled-coil peptide based design}

Molecular self-assembly is becoming a popular route to new supramolecular structures and molecular materials. The inspiration for such structures is commonly derived from selfassembling systems in nature [199]. The coiled-coil is one of the basic folding patterns of native proteins. It consists of two or more $\alpha$-helices winding together and forming a super-helix [219]. The primary structure of the coiled-coil motif is characterized by a heptad repeating sequence where the first and fourth are hydrophobic amino acid residues, while the others are polar. The distinctive feature of coiled-coils is the specific spatial recognition, association, and dissociation of the helices. Depending on their structure they may form homodimers, heterodimers with parallel or antiparallel orientation [199]. They provide an ideal model of protein biomaterials in which the higher structure may be predicted based on primary sequence. We designed two heptapeptad sequences with opposite charge (CCE and CCK) that selfassemble as antiparallel heterodimers (CCE: CYGG E VSALEKE VSALEKK NSALEKE VSALEKE VSALEK; CCK: CYGG K VSALKEK VSALKEE VSANKEK VSALKEK VSALKE) and synthesized HPMA copolymers grafted with these sequences, P-CCE and P-CCK [197]. As predicted, based on the design of peptides, the aqueous solutions of P-CCE or P-CCK alone did not form gels. In contrast, hydrogels self-assembled from equimolar mixtures of P-CCE/P-CCK within the full concentration range tested $(0.1-1.0 \mathrm{wt} . \%)$. The formation of hydrogels at concentrations as low as 0.1 wt.\% indicated a superior biorecognition of the two graft copolymers $[197,198]$.

To prove the concept of drug-free macromolecular therapeutics, two nanoconjugates were synthesized: a) Fab' fragment of 1F5 anti-CD20 antibody was conjugated to peptide CCE (Fab'- 
CCE); b) Multiple copies of complementary peptide CCK were attached as grafts to HPMA copolymer $\left(\mathrm{P}-(\mathrm{CCK})_{\mathrm{x}}\right)$. Exposure of Raji $\mathrm{B}$ cells to Fab'-CCE followed by $\mathrm{P}-(\mathrm{CCK})_{\mathrm{x}}$ initiated apoptosis due to crosslinking of the CD20 receptors mediated by antiparallel coiled-coil formation at the cell surface [220,221]. In vivo evaluation on SCID mice bearing systemically disseminated NHL Raji B cells the administration of two nanoconjugates (both consecutive or premixed) produced long-term survivors and eradicated lymphoma cells in blood and bone marrow [221].

Super-resolution imaging was used to quantify organizational changes in the plasma membrane after treatment with hybrid nanoconjugates, Fab'-CCE and $\mathrm{P}-(\mathrm{CCK})_{\mathrm{x}}$ [222]. Lipid rafts play a vital role in cell signaling, especially in apoptosis [223]. It is still unknown whether the nanoconjugates require lipid raft platforms to induce apoptosis and how the conjugates alter the lateral organizing of proteins in the membrane. We used methyl- $\beta$-cyclodextrin (M $\beta C D)$, a cholesterol chelator, to extract cholesterol, a component of lipid rafts, from the cell membrane [224] and latrunculin B (LatB), an actin destabilizer, to disassemble cortical actin and prevent lipid raft formation [225]. In order to validate the lipid raft-clustering hypothesis, we imaged CD20 and lipid raft clusters after nanoconjugate treatment. dSTORM (direct stochastic optical reconstruction microscopy) was used to provide super resolution images of Raji cellular membranes subjected to various treatments. Lipid rafts were tracked using Alexa Fluor 555 conjugated to cholera toxin B. CD20 distribution was tracked using fluorescently labeled Fab'MORF1-AF647. Lipid raft cluster size correlated with apoptosis induction after treatment with the nanoconjugates. Clusters greater than $100 \mathrm{~nm}$ in radii did not form in cells pre-treated with lipid raft disrupting molecules. Super-resolution images provided precise molecule location coordinates that could be used to determine density of bound conjugates, cluster size, and number of molecules per cluster [222].

In another study, multiple fluorescence imaging studies, including 2-channel FMT, 3D confocal microscopy, and 4-color FACS, were performed to prove that two conjugates (Fab'-CCE and P$\left.(\mathrm{CCK})_{\mathrm{x}}\right)$ can assemble at cell surface [226]. Confocal microscopy showed co-localization of two fluorescently labeled conjugates on NHL Raji cell surface, indicating "two-step" targeting specificity. The fluorescent images also revealed that these two conjugates could disrupt normal membrane lipid distribution and form lipid raft clusters, leading to cancer cell apoptosis. This "two-step" biorecognition capacity was further demonstrated in a NHL xenograft model, using fluorescent images at whole-body, tissue and cell levels [226].

\subsubsection{Evaluation of potential immunogenicity of CCE, CCK and their conjugates}

The aim of the study [227] was to a) assess general biocompatibility of the therapeutical system; and b) to compare the immune response to L- and D-CCE/CCK. In our previous research as well as in clinical trials it was demonstrated that short peptide spacers attached to HPMA copolymers do not exhibit immunogenicity [228,229]. However, the peptides used in coiled-coils contain 38 amino acid residues; this may be still not enough to initiate immune response when unbound, but these peptides may act as haptens when bound to HPMA copolymers or when associated with blood proteins. Consequently, we evaluated the immunogenicity in vitro and in vivo of free peptides, their conjugates with HPMA copolymer and with antibody fragment as well as their premixture (possible conformational epitopes). Both L- and D-peptides and conjugates were synthesized. The in vitro response was evaluated on RAW264.7 macrophages; the immunogenicity in vivo was performed in Balb/c mice following intravenous administration [227].

RAW264.7 cells were cultivated together with the tested compounds and cytokine production determined by ELISA (TNF- $\alpha, \mathrm{IL}-1 \beta, \mathrm{IL}-6$ and IL-10), and viability or changes in the surface markers (M1 vs. M2 polarization, activation markers) by flow cytometry. Lipopolysaccharide (LPS) served as positive control of activation (and M1 shift). Neither HPMA copolymer nor any 
peptide, either L- or D-, induced any response in murine macrophages. The component responsible for macrophage activation was the 1F5 Ab or its fragment. Interestingly, Press et al. treated 4 patients with 1F5 Ab and observed minimal treatment toxicities [230,231].

In vivo: the therapeutics based on L-peptides (MIX L, Fab'-L-CCE/P-L-CCK) did not induce substantially different $A b$ response than those based on $D$ peptides (MIX D; Fab'-D-CCE/P-DCCK). The titer and avidity of $A b$ induced by i.v. treatment with MIX $L$ or MIX D were generally low, slightly lower in case of MIX D, except for anti-Fab'-CCE IgM Ab. In general, there were detectable Abs, but no cellular response to the therapeutics administered i.v. The Ab response was predominantly directed against the Fab' part of the therapeutics [227]. In summary, the immunogenicity is acceptable for translation; to be on the safe side, humanization of the Fab' fragment is recommended before translation into the clinics.

\subsection{Morpholino oligonucleotide based design}

The biorecognition of oligopeptide sequences, CCE and CCK, resulted in the design of nanoconjugates with a robust anticancer effect. However, at physiological $\mathrm{pH}$ the peptide sequences did not possess a strong secondary structure. Their first contact was mediated by hydrophobic and electrostatic interactions. Once paired, they folded into highly organized antiparallel coiled-coil heterodimers. Consequently, an excess of the second nanoconjugate had to be used to achieve effective biorecognition in vivo [221].

With the aim to achieve excellent biorecognition at a $1: 1$ ratio of complementary moieties morpholino oligonucleotides have been selected based on their fast and efficient hybridization, stability in plasma, and water solubility [232,233].

Nucleic acid hybridization, such as the formation of a DNA double helix is composed of WatsonCrick base pairing, i.e., hydrogen bonding of $\mathrm{A} / \mathrm{T}$ and $\mathrm{C} / \mathrm{G}$, between two single-stranded polynucleotides with complementary sequences. The conformation is further stabilized by base stacking, i.e., $\Pi-\pi$ interaction of neighboring bases on the same strand. DNA has been used as building blocks for biomaterials design [234,235] and functional nanostructures for drug delivery [236]. Over the years, a variety of artificial oligonucleotides with chemically modified backbones have been synthesized [237]. These non-phosphodiester backbones are nuclease resistant and stable in the body; thus, they are suitable for biopharmaceutical applications. We designed a pair of phosphorodiamidate morpholino (MORF) oligomers, MORF1 (5'GAGTAAGCCAAGGAGAATCAATATA-linker-amine-3') and MORF2 (5'TATATTGATTCTCCTTGGCTTACTC-linker-amine-3'), as the biorecognition motifs for the second-generation "drug-free" therapeutic system [232]. The MORF oligonucleotides are charge neutral, resulting in significantly stronger binding than natural DNA and RNA [238]. Hybridization of MORF pairs has well-defined binding specificity, which prevents potential offtarget effects [239]. In addition, MORF oligonucleotides have good aqueous solubility and favorable pharmacokinetics [240]. The sequences of MORF1 and MORF2 were designed to achieve optimal binding efficiency and minimal off-targets with human and murine mRNA, and to prevent self-complementarity [232]. This new therapeutic system is composed of two hybrid conjugates: (1) anti-CD20 Fab' linked to MORF1 (Fab'-MORF1), and (2) HPMA copolymers grafted with multiple MORF2 $\left(\mathrm{P}-(\mathrm{MORF} 2)_{\mathrm{x}}\right)$. The two conjugates self-assemble via MORF1MORF2 hybridization at the surface of $\mathrm{CD}^{2} 0^{+} \mathrm{B}$-cells, crosslink CD20 antigens and initiate apoptosis [232]. 


\subsection{Advantages and general applicability of the new paradigm}

The therapeutic system comprises a pretargeting component (anti-CD20 Fab' conjugated with MORF1) and a crosslinking component ( $N$-(2-hydroxypropyl)methacrylamide (HPMA) copolymer grafted with multiple complementary MORF2). Consecutive treatment with the two components resulted in CD20 clustering on the cell surface and effectively killed malignant Bcells in vivo. To enhance therapeutic efficacy, a two-step pretargeting approach was employed. We showed that the time lag between the two doses can be optimized based on pharmacokinetics and biodistribution of the Fab'-MORF1 conjugate. In a mouse model of human non-Hodgkin lymphoma (NHL), increasing the time lag from $1 \mathrm{~h}$ to $5 \mathrm{~h}$ resulted in dramatically improved tumor growth inhibition and animal survival. When the $5 \mathrm{~h}$ interval was used, the nanotherapy was more efficacious than rituximab and led to complete eradication of lymphoma cells with no signs of metastasis or disease recurrence [241].
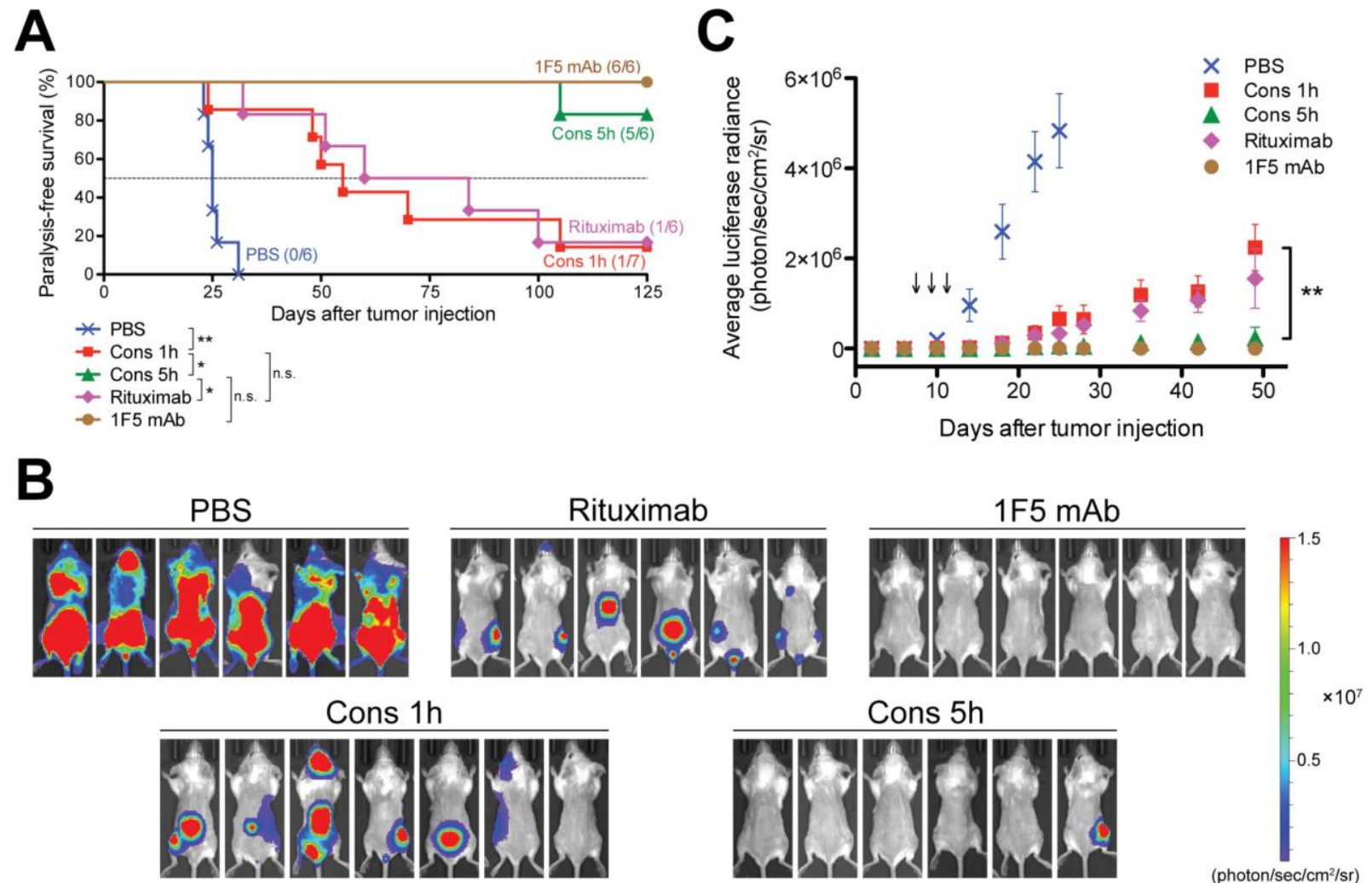

Figure 6. In vivo efficacy of drug-free macromolecular therapeutics against systemic B-cell lymphoma. SCID mice were injected with luciferase-expressing Raji cells $\left(4 \times 10^{6}\right)$ via the tail vein on day 0 . Three doses of each treatment were administered on days 7,9 , and $11(n=6$ or 7$)$. PBS: mice injected with PBS; Cons $1 \mathrm{~h}$ : consecutive treatment of Fab'-MORF1 and P-MORF2, $1 \mathrm{~h}$ interval; Cons $5 \mathrm{~h}$ : consecutive treatment of Fab'-MORF1 and P-MORF2, $5 \mathrm{~h}$ interval; Rituximab; 1 F5 mAb. (A) Paralysis-free survival of mice presented in a Kaplan-Meier plot. Numbers of long-term survivors in each group are indicated. Statistics was performed with log-rank test $\left({ }^{*}: p<0.05,{ }^{* *}: p<0.005\right.$, n.s.: no significant difference). (B) In vivo bioluminescence images at 25 days post-tumor injection. Mice were i.p. injected with $3 \mathrm{mg}$ firefly Dluciferin $15 \mathrm{~min}$ prior to imaging. (C) Whole-body bioluminescence intensity of mice. Data are shown as mean \pm SEM ( $n=6$ or 7$)$. Statistics was performed by student's $t$ test $\left({ }^{* *}: p<0.005\right)$. Black arrow: dose administration. Reprinted with permission from ref. [241].

We further evaluated the nanomedicines using cells from 10 patients with chronic lymphocytic leukemia (CLL) [242]. Apoptosis and cytotoxicity were observed in 8 patients including two with the 17p13 deletion, a high-risk prognostic factor. Additionally, cells from patients with mantle cell lymphoma also responded to the drug-free therapy [241]. 
The drug-free system is a new paradigm in macromolecular therapeutics. Its main feature is the absence of a low molecular weight drug. Other favorable features are: a) Pretargeting - the twostep treatment permits to manipulate the pharmacokinetics by separating the targeting modality from the effector modality; b) Multivalency - the second nanoconjugate is multivalent and it was demonstrated that the efficiency relates to its valency [232]; c) The system is immune independent. The nanoconjugates directly induce apoptosis without the need for immune activation. The drug-free macromolecular therapy is distinct from mAb-based immunotherapy. Here synthetic effectors are operative that replace the function of immune effector cells. This approach may benefit patients that do not respond to immunotherapies [243].

\section{Conclusions and future prospects}

Scientifically, the design principles for polymer-based nanomedicines are well defined; the challenge is to combine the efficient design of the conjugates with the understanding of the biological features of cancer, including heterogeneity of cancer cells, tumor microenvironment, and metastasis [160]. The remarkable progress in imaging techniques that permit non-invasive monitoring of the fate of conjugates will undoubtedly contribute to a more rational design of polymer therapeutics and theranostics [244,245]. However, a qualitative change in the approach to design and treatment is needed for successful translation to the clinics.

The advantage of the second generation (backbone degradable) conjugates over both, first generation conjugates and free drugs was clearly demonstrated. These new conjugates are long-circulating; they are composed from enzymatically cleavable sequences and synthetic blocks in an alternating arrangement. In addition to enhanced efficacy, the synthesis of biodegradable diblock HPMA copolymer conjugates using a RAFT chain transfer agent that contains a degradable peptide sequence flanked by two dithiobenzoate groups, is clearly a scalable proces.

Drug-free macromolecular therapeutics is a new paradigm in polymer-based nanomedicines. It is an example of qualitatively new design approach. The absence of low molecular weight drugs and independence from immune activation render the method applicable in many areas. In addition to NHL therapy, it may be used for the treatment of other B cell related diseases rheumatoid arthritis, idiopathic thrombocytopenic purpura, hemolytic anemia [246-247], and multiple sclerosis [249]. Moreover, in addition to CD20, other slowly internalizing receptors may be used as targets, such as CD45, death receptor 4, prostate cell antigen, and carcinoembryonic antigen [200].

The scientific knowledge and experience from preclinical and clinical research are the basis for the possible translation of macromolecular therapeutics into the clinics within the next decade.

\section{Acknowledgements}

The research described in this review has been supported by $\mathrm{NIH}$ grants (recently CA51578, CA132831, GM069847, EB005288, TW006260, CA156933, and GM095606), Department of Defense (W81XWH-13-1-0160), and University of Utah Research Foundation. We thank our coworkers and numerous collaborators. We are truly indebted to all of them; their scientific contributions are reflected in the references. 


\section{References}

[1] http://www.homedialysis.org/home-dialysis-basics/machines-and-supplies/dialysismuseum

[2] W. Peters, The history of biomaterials used for breast augmentation, in: W. Peters, $\mathrm{H}$. Brandon, K.L. Jerina, C. Wolf, V.L. Young (Eds.), Biomaterials in Plastic Surgery: Breast Implants, Woodhead Publishing, Cambridge, UK, 2012, pp. 1-39.

[3] J. Curtis, A. Colas, Medical application of silicones, in: B.D. Ratner, A.S. Hoffman, F.J. Schoen, J.E. Lemons (Eds.), Biomaterials Science, 3rd Ed., Academic Press, Oxford, UK, 2013, pp. 1106-1116.

[4] O. Wichterle, D. Lím, Hydrophilic gels for biological use, Nature 185 (1960)117-118.

[5] O. Wichterle, U.S. Patent 3,361 858 (1968)

[6] J. Kopeček, Hydrogels: From soft contact lenses and implants to self-assembled nanomaterials, J. Polym. Sci. Part A: Polym. Chem. 47 (2009) 5929-5946.

[7] Z. Voldřich, Z. Tománek, J. Vacík, J. Kopeček, Long-term experience with the poly(glycol monomethacrylate) gel in plastic operations of the nose, J. Biomed. Mater. Res. 9 (1975) 675-685.

[8] H. Jatzkewitz, Peptamin (glycyl-L-leucyl-mescaline) bound to blood plasma expander (polyvinylpyrrolidone) as a new depot form of a biologically active primary amine (mescaline), Z. Naturforsch. 10b (1955) 27-31.

[9] N.I. Givetal, S.N. Ushakov, E.F. Panarin, G.O. Popova, Experimantal studies on penicillin polymer derivatives (in Russian), Antibiotiki 10 (1965) 701-706.

[10] K.I. Shumikina, E.F. Panarin, S.N. Ushakov, Experimental study of polymer salts of penicillins (in Russian), Antibiotiki 11 (1966) 767-770.

[11] E.F. Panarin, S.N. Ushakov, Synthesis of polymer salts and amidopenicillines (in Russian), Khim. Pharm. Zhur. 2 (1968) 28-31.

[12] G. Mathé, T.B. Loc, J. Bernard, Effect sur la leucémie L1210 de la souris d'une combinaison par diazotation d'a méthoptérine et de $\gamma \square$ globulines de hamsters porteurs de cette leucémie par hétérogreffe, Compte-rendus del'Académie des Sciences 3 (1958) 1626-1628.

[13] C. De Duve, T. De Barsy, B. Poole, A. Trouet, P. Tulkens, F. van Hoof, Lysosomotropic agents, Biochem. Pharmacol. 23 (1974) 2495-2531.

[14] H. Ringsdorf, Structure and properties of pharmacologically active polymers, J. Polym. Sci., Polym. Symp. 51 (1975) 135-153.

[15] J. Kopeček, Soluble biomedical polymers, Polim. Med. 7 (1977) 191-221.

[16] A. Abuchowski, J.R. McCoy, N.C. Palczuk, T. van Es, F.F. Davis, Effect of covalent attachment of polyethylene glycol on immunogenicity and circulation time of bovine liver catalase, J. Biol. Chem. 252 (1977) 3582-3586.

[17] P.J. Kierstead, H. Okochi, V.J. Venditto, T.C. Chung, S. Kivimae, J.M.J. Fréchet, F.C. Szoka, The effect of polymer backbone chemistry on the induction of the accelerated blood clearance in polymer modified liposomes, J. Controlled Release 213 (2015) 1-9.

[18] A.S. Hoffman, The origins and evolution of "controlled" drug delivery systems, J. Controlled Release 132 (2008) 153-163.

[19] J. Kopeček, Biomaterials and drug delivery - past, present, and future, Mol. Pharmaceutics 7 (2010) 922-925.

[20] N.L. Krinick, J. Kopeček, Soluble polymers as targetable drug carriers, in: R.L. Juliano (Ed.), Targeted Drug Delivery (Handbook of experimental pharmacology, vol. 100), Springer, Berlin, 1991, pp. 105-179.

[21] H.-C. Chiu, P. Kopečková, S.S. Deshmane, J. Kopeček, Lysosomal degradation of poly( $\alpha$-amino acids), J. Biomed. Mater. Res. 34 (1997) 381-392.

[22] H.-C. Chiu, Č. Koňák, P. Kopečková, J. Kopeček, Enzymatic degradation of poly(ethylene glycol) modified dextrans, J. Bioact. Comp. Polym. 9 (1994) 388-410.

[23] J.B. Lloyd, Lysosomal membrane permeability: Implications for drug delivery, Adv. Drug Deliv. Rev. 41 (2000) 189-200. 
[24] J. Kopeček, The potential of water-soluble polymeric carriers in targeted and site-specific drug delivery, J. Controlled Release 11 (1990) 279-290.

[25] L.Šprincl, J. Exner, O. Štěrba, J. Kopeček, New types of synthetic infusion solutions. III Elimination and retention of poly[ $N$-(2-hydroxypropyl)methacrylamide] in a test organism, J. Biomed. Mater. Res. 10 (1976) 953-963.

[26] L.W. Seymour, R. Duncan, J. Strohalm, J. Kopeček, Effect of molecular weight of N-(2hydroxypropyl)methacrylamide copolymers on body distribution and rate of excretion after subcutaneous, intraperitoneal and intravenous administration to rats, J. Biomed. Mater. Res. 21 (1987) 1341-1358.

[27] L.W. Seymour, Y. Miyamoto, H. Maeda, M. Bereton, J. Strohalm, K. Ulbrich, R. Duncan, Influence of molecular weight on passive tumor accumulation of a soluble macromolecular drug carrier, Eur. J. Cancer 31A (1995) 766-770.

[28] Y. Noguchi, J. Wu, R. Duncan, J. Strohalm, K. Ulbrich, T. Akaike, H. Maeda, Early phase tumor accumulation of macromolecules: a great difference in clearance rate between tumors and normal tissue, Jpn. J. Cancer Res. 89 (1998) 307-314.

[29] M. Kissel, P. Peschke, V. Šubr, K. Ulbrich, J. Schumacher, J. Debus, E. Friedrich, Synthetic macromolecular drug carriers: biodistribution of poly[ $(\mathrm{N}-2-$ hydroxypropyl)methacylamide] copolymers and their accumulation in solid rat tumors, PDA J. Pharm. Sci. Technol. 55 (2001) 191-201.

[30] M. Dvořák, P. Kopečková, J. Kopeček, High-molecular weight HPMA copolymer adriamycin conjugates, J. Controlled Release 60 (1999) 321-332.

[31] J.-G. Shiah, M. Dvořák, P. Kopečková, Y. Sun, C.M. Peterson, J. Kopeček, Biodistribution and antitumor efficacy of long-circulating $\mathrm{N}$-(2hydroxypropyl)methacrylamide copolymer-doxorubicin conjugates in nude mice, Eur. J. Cancer 37 (2001) 131-139.

[32] W. Hespe, A.M. Meier, Y.J. Blankwater, Excretion and distribution studies in rats with two forms of 14carbon-labeled polyvinylpyrrolidone with a relatively low mean molecular weight after intravenous administration, Drug Res. 27 (1977) 1158-1162.

[33] T. Yamaoka, Y. Tabata, Y. Ikada, Body distribution profile of polysaccharides after intravenous administration. Drug Delivery 1 (1993) 75-82.

[34] J. Kopeček, Soluble polymers in medicine, in: D.F. Williams (Ed.), Systemic Aspects of Biocompatibility, Vol. II, CRC Press, Boca Raton, Florida, 1981, pp. 159-180.

[35] T. Yamaoka, Y. Tabata, Y. Ikada, Fate of water-soluble polymers administered via different routes, J. Pharm. Sci. 84 (1995) 349-354.

[36] T. Lammers, R. Kühnlein, M. Kissel, V. Subr, T. Etrych, R. Pola, M. Pechar, K. Ulbrich, G. Storm, P. Huber, P. Peschke, Effect of physicochemical modification on the biodistribution and tumor accumulation of HPMA copolymers, J. Controlled Release 110 (2005) 103-118.

[37] J. Liu, H. Bauer, J. Callahan, P. Kopečková,'H. Pan, J. Kopeček, Endocytic uptake of a large array of HPMA copolymers: Elucidation into the dependence on the physicochemical characteristics, J. Controlled Release 143 (2010) 71-79.

[38] S.D. Conner, S.L. Schmid, Regulated portals of entry into the cell, Nature 422 (2003) 3744.

[39] M. Kirkham, R.G. Parton, Clathrin-independent endocytosis: new insights into caveolae and non-caveolar lipid raft carriers, Biochim. Biophys. Acta 1746 (2005) 349-363.

[40] S. Mayor, R.F. Pagano, Pathways of clathrin-independent endocytosis, Nat. Rev. Mol. Cell Biol. 8 (2007) 603-612.

[41] Q. Gong, C. Huntsman, D. Ma, Clathrin-independent internalization and recycling, J. Cell Mol. Med. 12 (2008) 126-144.

[42] M.C. Kerr, R.D. Teasdale, Defining macropinocytosis, Traffic 10 (2009) 364-371.

[43] A. Rebuffat, A. Bernasconi, M. Ceppi, H. Wehrli, S. Brenz Verca, M. Ibrahim, B.M. Frey, F.J. Frey, S. Rusconi, Selective enhancement of gene transfer by steroid-mediated gene delivery, Nature Biotechnol. 19 (2001) 1155-1161. 
[44] J. Callahan, J. Kopeček, Semitelechelic HPMA copolymers functionalized with triphenylphosphonium as drug carriers for membrane transduction and mitochondrial localization, Biomacromolecules 7 (2006) 2347-2356.

[45] V. Cuchelkar, P. Kopečková, J. Kopeček, Novel HPMA copolymer-bound constructs for combined tumor and mitochondrial targeting, Mol. Pharmaceutics 5 (2008) 696-709.

[46] A. Muratovska, R.N. Lightowlers, R.W. Taylor, D.M. Turnbull, R.A. Smith, J.A. Wilce, S.W. Martin, M.P. Murphy, Targeting peptide nucleic acid (PNA) oligomers to mitochondria within cells by conjugation to lipophilic cations: implications for mitochondrial DNA replication, expression and disease, Nucleic Acids Res. 29 (2001) 1852-1863.

[47] A. Filipovska, M.R. Eccles, R.A. Smith, M.P. Murphy, Delivery of antisense peptide nucleic acids (PNAs) to the cytosol by disulfide conjugation to a lipophilic cation, FEBS Lett. 556 (2004) 180-186.

[48] S. Biswas, N.S. Dodwadkar, A. Piroyan, V.P. Torchilin, Surface conjugation of triphenylphosphonium to target poly(amidoamine) dendrimers to mitochondria, Biomaterials 33 (2012) 4773-4782.

[49] E.R. Bielski, Q. Zhong, M. Brown, S.R. da Rocha, Effect of conjugation density of triphenylphosphonium cation on the mitochondrial targeting of poly(amidoamine) dendrimers, Mol. Pharmaceutics 12 (2015) 3043-3053.

[50] S. Biswas, N.S. Dodwadkar, P.P. Deshpande, V.P. Torchilin, Liposomes loaded with paclitaxel and modified with novel triphenylphosphonium-PEG-PE conjugate possess low toxicity, target mitochondria and demonstrate enhanced antitumor effects in vitro and in vivo, J. Controlled Release 159 (2012) 393-402.

[51] Y. Yang, N. Gao, Y. Hu, C. Jia, T. Chou, H. Du, H. Wang, Gold nanoparticle enhanced photodynamic therapy: effects of surface charge and mitochondrial targeting, Ther. Deliv. 6 (2015) 307-321.

[52] S. Marrache, S. Dhar, Engineering of blended nanoparticle platform for delivery of mitochondria-acting therapeutics, Proc. Natl. Acad. Sci. USA 109 (2012) 16288-16293.

[53] N. Panté, M. Kann, Nuclear pore complex is able to transport macromolecules with diameters of about $39 \mathrm{~nm}$, Mol. Biol. Cell 13 (2002) 425-434.

[54] P. L. Paine, L. C. Moore, S. B. Horowitz, Nuclear envelope permeability, Nature 254 (1975) 109-114.

[55] C.M. Feldherr, D. Akin, The location of the transport gate in the nuclear pore complex, J. Cell Sci. 110 (1997) 3065-3070

[56] J. Callahan, P. Kopečková, J. Kopeček, The intracellular traffricking and subcellular distribution of a large array of HPMA copolymer conjugates, Biomacromolecules 10 (2009) 1704-1714.

[57] S. Frey, R.P. Richter, D. Görlich, FG-rich repeats of nuclear pore proteins form a threedimensional meshwork with hydrogel-like properties, Science 314 (2006) 815-817.

[58] J. Kopeček, P. Kopečková, Č. Koňák, Biorecognizable polymers: Design, structure, bioactivity, J. Macromol. Sci. A - Pure Appl. Chem. A34 (1997) 2103-2117.

[59] K. Ulbrich, Č. Koňák, Z. Tuzar, J. Kopeček, Solution properties of drug carriers based on poly[N-(2-hydroxypropyl)methacrylamide] containing biodegradable bonds, Makromol. Chem. 188 (1987) 1261-1272.

[60] Z. Gu, V. Omelyanenko, P. Kopečková, J. Kopeček, Č. Koňák, Association of a substituted zinc(II) phthalocyanine- $N$-(2-hydroxypropyl)methacylamide copolymers, Macromolecules 28 (1995) 8375-8380.

[61] H. Ding, W.M. Prodinger, J. Kopeček, Two-step fluorescence screening of CD21-binding peptides with one-bead one-compound library and investigation of binding properties of $\mathrm{N}$-(2-hydroxypropyl)methacrylamide copolymer-peptide conjugates, Biomacromolecules 7 (2006) 3037-3046.

[62] H. Pan, P. Kopečková, D. Wang, J. Yang, S. Miller, J. Kopeček, Water-soluble HPMA copolymer--prostaglandin E1 conjugates containing a cathepsin $\mathrm{K}$ sensitive spacer, J. Drug Targeting 14 (2006) 425-435. 
[63] T. Wang, J.R. Upponi, V.P. Torchilin, Design of multifunctional non-viral gene vectors to overcome physiological barriers: dilemmas and strategies, Int. J. Pharm. 427 (2012) 3-20.

[64] P. Chandna, J.J. Khandare, E. Ber, L. Rodriguez-Rodriguez, T. Minko, Multifunctional tumor-targeted polymer-peptide-drug delivery system for treatment of primary and metastatic cancers, Pharmaceutical Res. 27 (2010) 2296-2306.

[65] B.S. Lee, M. Fujita, N.M. Khazenzon, K.A. Wawrowsky, S. Wachsmann-Hogiu, D.L. Farkas, K.L. Black, J.Y. Ljubimova, E. Holler, Polycefin, a new prototype of a multifunctional nanoconjugate based on poly(beta-L-malic acid) for drug delivery, Bioconjugate Chem. 17 (2006) 317-326.

[66] H. Ding, P. Kopečková, J. Kopeček, Self-association properties of HPMA copolymers containing an amphipathic heptapeptide, J. Drug Targeting 15 (2007) 465-474.

[67] M. Allmeroth, D. Moderegger, B. Biesalski, K. Koynov, F. Rötsch, O. Thews, R. Zentel, Modifying the body distribution of HPMA-based copolymers by molecular weight and aggregate formation, Biomacromolecules 12 (2011) 2841-2849.

[68] K. Ulbrich, V. Šubr, Structural and chemical aspects of HPMA copolymers as drug carriers, Adv. Drug Deliv. Rev. 62 (2010) 150-166.

[69] M.E. Fox, F.C. Szoka, J.M. Fréchet, Soluble polymer carriers for the treatment of cancer: the importance of molecular architecture, Acc. Chem. Res. 42 (2009) 1141-1151.

[70] D. Wang, P. Kopečková, T. Minko, V. Nanayakkara, J. Kopeček, Synthesis of starlike N(2-hydroxypropyl)methacrylamide copolymers: Potential drug carriers, Biomacromolecules 1 (2000) 313-319.

[71] T. Etrych, J. Strohalm, P. Chytil, B. Ríhová, K. Ulbrich, Novel star HPMA-based polymer conjugates for paasive targeting to solid tumors, J. Drug Targeting 19 (2011) 874-889.

[72] T. Etrych, L. Kovář, J. Strohalm, P. Chytil, B. Říhová, K. Ulbrich, Biodegradable star HPMA copolymer-drug conjugates: Biodegradability, distribution and anti-tumor efficacy, J. Controlled Release 154 (2011) 241-248.

[73] T. Etrych, T. Mrkvan, B. Říhová, K. Ulbrich, Star-shaped immunoglobulin-containing HPMA based conjugates with doxorubicin for cancer therapy, J. Controlled Release 122 (2007) 31-38.

[74] T. Etrych, J. Strohalm, L. Kovář, M. Kabešová, B. Říhová, K. Ulbrich, HPMA copolymer conjugates with reduced anti-CD20 antibody for cell-specific drug targeting. I. Synthesis and in vitro evaluation of binding efficacy and cytostatic activity, J. Controlled Release 140 (2009) 18-26.

[75] J. Kopeček, Synthesis of tailor-made soluble polymeric drug carriers, in: J.M. Anderson, S.W. Kim (Eds.), Recent Advances in Drug Delivery Systems, Plenum, New Yorh 1984, pp. 41-62.

[76] D. Putnam, J. Kopeček, Polymer conjugates with anticancer activity, Adv. Polym. Sci. 122 (1995) 55-123.

[77] D.B. Rozema, D.L. Lewis, D.H. Wakefield, So.C. Wong, J.J. Klein, P.L. Roesch, S.L. Bertin, T.W. Reppen, Q. Chu, A.V. Blokhin, J.E. Hagstrom, J.A. Wolff, Dynamic polyconjugates for targeted in vivo delivery of siRNA to hepatocytes, Proc. Natl. Acad. Sci. USA 104 (2007) 12982-12987.

[78] D.B. Rozema, K. Ekena, D.L. Lewis, A.G. Loomis, J.A. Wolff, Endosomolysis by masking of a membrane-active agent (EMMA) for cytoplasmic release of macromolecules. Bioconjugate Chem. 14, 51-57 (2003).

[79] P. Rejmanová, J. Kopeček, R. Duncan, J.B. Lloyd, Stability in rat plasma and serum of lysosomally degradable oligopeptide sequences in $N$-(2-hydroxypropyl)methacrylamide copolymers, Biomaterials 6 (1985) 45-48.

[80] J. Kopeček, P. Rejmanová, Enzymatically degradable bonds in synthetic polymers, in: Controlled Drug Delivery, Vol. I, S. D. Bruck (Ed.), CRC Press, Boca Raton, Florida, 1983, pp. 81-124.

[81] J. Kopeček, Biodegradation of polymers for biomedical use, in: IUPAC Macromolecules, H. Benoit, P. Rempp (Eds.), Pergamon, Oxford, 1982, pp. 305-320. 
[82] J. Kopeček, P. Kopečková, HPMA copolymers: Origins, early developments, present, and future, Adv. Drug Deliv. Rev. 62 (2010) 122-149.

[83] J. Kopeček, P. Rejmanová, V. Chytrý, Polymers containing enzymatically degradable bonds 1. Chymotrypsin catalyzed hydrolysis of $p$-nitroanilides of phenylalanine and tyrosine attached to side-chains of copolymers of $\mathrm{N}$-(2-hydroxypropyl)methacrylamide, Makromol. Chem. 182 (1981) 799-809.

[84] K. Ulbrich, J. Strohalm, J. Kopeček, Polymers containing enzymatically degradable bonds. 3. Poly[N-(2-hydroxypropyl)methacrylamide] chains connected by oligopeptide sequences cleavable by trypsin, Makromol. Chem. 182 (1981) 1917-1928.

[85] K. Ulbrich, E.I. Zacharieva, B. Obereigner, J. Kopeček, Polymers containing enzymatically degradable bonds. 5. Hydrophilic polymers degradable by papain, Biomaterials 1 (1980) 199-204.

[86] J. Kopeček, Controlled degradability of polymers - a key to drug delivery systems, Biomaterials 5 (1984) 19-25.

[87] J. Kopeček, I. Cífková, P. Rejmanová, J. Strohalm, B. Obereigner, K. Ulbrich, Polymers containing enzymatically degradable bonds. 4. Preliminary experiments in vivo, Makromol. Chem. 182 (1981) 2941-2949.

[88] R. Duncan, H.C. Cable, J.B. Lloyd, P. Rejmanová, J. Kopeček, Polymers containing enzymatically degradable bonds. 7 . Design of oligopeptide side-chains in poly[N-(2hydroxypropyl)methacrylamide] copolymers to promote efficient degradation by lysosomal enzymes, Makromol. Chem. 184 (1983) 1997-2008.

[89] V. Šubr, J. Kopeček, J. Pohl, M. Baudyš, V. Kostka, Cleavage of oligopeptide side-chains in $\mathrm{N}$-(2-hydroxypropyl)methacrylamide copolymers by mixtures of lysosomal enzymes, J. Controlled Release 8 (1988) 133-140.

[90] P. Rejmanová, J. Pohl, M. Baudyš, V. Kostka, J. Kopeček, Polymers containing enzymatically degradable bonds. 8. Degradation of oligopeptide sequences in $\mathrm{N}-(2-$ hydroxypropyl)methacrylamide copolymers by bovine spleen cathepsin B, Makromol. Chem. 184 (1983) 2009-2020.

[91] A. Nan, H. Ghandehari, C. Harbert, H. Siavash, N, Nikitakis, M. Reynolds, J.J. Sauk, Water-soluble polymers for targeted drug delivery to human squamous carcinoma of head and neck, J. Drug Target. 13 (2005) 190-197.

[92] Z.H. Peng, M. Sima, M.E. Salama, P. Kopečková, J. Kopeček, Spacer length impacts the efficacy of targeted docetaxel conjugates in prostate-specific membrane antigen expressing prostate cancer, J. Drug Target. 21 (2013) 968-980.

[93] Z.-H. Peng, J. Kopeček, Enhancing accumulation and penetration of HPMA copolymer doxorubicin conjugates in 2D and 3D prostate cancer cells via iRGD conjugation with an MMP-2 cleavable spacer, J. Am. Chem. Soc. 137 (2015) 6726-6729.

[94] R. Zhang, J. Yang, Y. Zhou, P.J. Shami, J. Kopeček, N-(2-Hydroxypropyl)methacrylamide copolymer-drug conjugates for combination chemotherapy of acute myeloid leukemia, Macromol. Biosci. (2015) doi: 10.1002/mabi201500193.

[95] J. Yang, R. Zhang D.C. Radford, J. Kopeček, FRET-trackable biodegradable HPMA copolymer-epirubicin conjugates for ovarian carcinoma therapy, J. Controlled Release, submitted.

[96] P.A. Vasey, S.B. Kaye, R. Morrison, C. Twelves, P. Wilson, R. Duncan, A.H. Thomson, L.S. Murray, T.E. Hilditch, T. Murray, S. Burtles, D. Fraier, E. Frigerio, J. Cassidy, and on behalf of the Cancer Research Campaign Phase I/II Committee, Phase I clinical and pharmacokinetic study of PK1 [N-(2-hydroxypropyl)methacrylamide copolymer doxorubicin]: first member of a new class of chemotherapeutic agents-drug-polymer conjugates, Clin. Cancer Res. 5 (1999) 83-94.

[97] L.W. Seymour, D.R. Ferry, D. Anderson, S. Hesslewood, P.J. Julyan, R. Poyner, J. Doran, A.M. Young, S. Burtles, D.J. Kerr, Hepatic drug targeting: phase I evaluation of polymerbound doxorubicin, J. Clin. Oncol. 20 (2002) 1668-1676.

[98] B. Říhová, Clinical experience with anthracycline antibiotics-HPMA copolymer-human immunoglobulin conjugates, Adv. Drug Deliv. Rev. 61 (2009) 1149-1158. 
[99] H. Dozono, S. Yanazume, H. Nakamura, T. Etrych, P. Chytil, K. Ulbrich, J. Fang, T. Arimura, T. Douchi, H. Kobayashi, M. Ikoma, H. Maeda, HPMA copolymer-conjugated pirarubicin in multimodal treatment of a patient with stage IV prostate lung cancer and extensive lung and bone metastases, Target Oncol. Epub ahead of print July 222015

[100] S.O. Doronina, T.D. Bovee, D.W. Meyer, J.B. Miyamoto, M.E. Anderson, C.A. MorrisTilden, P.D. Senter, Novel peptide linkers for highly potent antibody-auristatin conjugate. Bioconjugate Chem. 19 (2008) 1960-1963.

[101] P.J. Burke, P.D. Senter, D.W. Meyer, J.B. Miyamoto, M. Anderson, B.E. Toki, G. Manikumar, M.C. Wani, D.J. Krol, S.C. Jeffrey, Design, synthesis, and biological evaluation of antibody-drug conjugatets comprised of potent camptothecin analogues. Bioconjugate Chem. 20 (2009) 1242-1250.

[102] Y. Chau, F.E. Tan, R. Langer, Synthesis and characterization of dextran-peptidemethotrexate conjugates for tumor targeting via mediation by matrix metalloproteinase II and matrix metalloproteinase IX, Bioconjugate Chem. 15 (2004) 931-941.

[103] B.E. Toki, C.G. Cerveny, A.F. Wahl, P.D. Senter, Protease-mediated fragmentation of $p$ amidobenzyl ethers: a new strategy for the activation of anticancer prodrugs, J. Org. Chem. 67 (2002) 1866-1872.

[104] G.M. Dubowchik, R.A. Firestone, L. Padilla, D. Willner, S.J. Hofstead, K. Mosure, J.O. Knipe, S.J. Lasch, P.A. Trail, Cathepsin B-labile dipeptide linkers for lysosomal release of doxorubicin from internalizing immunoconjugates: Model studies of enzymatic drug release and antigen-specific in vitro anticancer activity, Bioconjugate Chem. 13 (2002) 855-869.

[105] K. Ulbrich, V. Šubr, Polymeric anticancer drugs with pH-controlled activation, Adv, Drug Deliv. Rev. 56 (2004) 1023-1050.

[106] H. Nakamura, T. Etrych, P. Chytil, M. Ohkubo, J. Fang, K. Ulbrich, H. Maeda, Two step mechanism of tumor selective delivery of $\mathrm{N}$-(2-hydroxypropyl)methacrylamide copolymer conjugated with piarubicin via an acid-cleavable linkage, J. Controlled Release 174 (2014) 81-87.

[107] T. Etrych, M. Jelínková, B. Říhová, K. Ulbrich, New HPMA copolymers containing doxorubicin bound via $\mathrm{pH}$-sensitive linkage: synthesis and preliminary in vitro and in vivo properties, J. Controlled Release 73 (2001) 89-102.

[108] W.-C. Shen, H.J.-P. Ryser, Cis-aconityl spacer between daunomycin and macromolecular carriers: a model of $\mathrm{pH}$-sensitive linkage releasing drug from a lysosomotropic conjugate, Biochem. Biophys. Res. Commun. 102 (1981) 1048-1054.

[109] P. Chytil, T. Etrych, Č. Koňák, M. Šírová, B. Říhová, K. Ulbrich, Properties of HPMA copolymer-doxorubicin conjugates with $\mathrm{pH}$-controlled activation: effect of polymer chain modification, J. Controlled Release 115 (2006) 26-36.

[110] D.P. Jones, J.L. Carlson, V.C. Mody, J. Cai, M.J. Lynn, P. Sternberg, Redox state of glutathione in human plasma, Free Radic. Biol. Med. 28 (2000) 625-635.

[111] G. Saito, J. A. Swanson, K. D. Lee, Drug delivery strategy utilizing conjugation via reversible disulfide linkages: role and site of cellular reducing activities, Adv. Drug Deliv. Rev. 55 (2003) 199-215.

[112] H.F. Gilbert, Thiol/disulfide exchange equilibria and disulfide bond stability, Methods Enzymol. 251 (1995) 8-28.

[113] A. Meister, M.E. Anderson, Glutathione, Annu. Rev. Biochem. 52 (1983) 711-760.

[114] D. Gainey, S. Short, K.L. McCoy, Intracellular location of cysteine transport activity correlates with productive processing of antigen disulfide, J. Cell Physiol. 168 (1996) 248254.

[115] J.B. Lloyd, Disulfide reduction in lysosomes. The role of cysteine, Biochem. J. 237 (1986) 271-272.

[116] B. Arunachalam, U.T. Phan, H.J. Geuze, P. Cresswell, Enzymatic reduction of disulfide bonds in lysosomes: characterization of a gamma-interferon-inducible lysosomal thiol reductase (GILT), Proc. Natl. Acad. Sci. USA 97 (2000) 745-750 
[117] E. Wagner, M. Zenke, M. Cotton, H. Beug, M.L. Birnstiel, Transferrin-polycation conjugates as carriers for DNA uptake into cells, Proc. Natl. Acad. Sci. USA 87 (1990) 3410-3414.

[118] C. Zhu, M. Zheng, F. Meng, F.M. Mickler, N. Ruthardt, X. Zhu, Z. Zhong, Reversibly shielded DNA polyplex based on bioreducible PDMAEMA-SS-PEG-SSPDMAEMA triblock copolymers mediate markedly enhanced nonviral gene transfection, Biomacromolecules 13 (2012) 769-778.

[119] H. Baigude, J. Su, J. McCarroll, T.M. Rana, In vivo delivery of RNAi by reducible interfering nanoparticles (iNOPs), ACS Med. Chem. Lett. 4 (2013) 720-723.

[120] A. Scomparin, D. Polyak, A. Krivitsky, R. Satchi-Fainaro, Achieving successful delivery of oligonucleotides - From physicochemical characterization to in vivo evaluation, Biotechnol. Adv. (2015) doi: 10.1016/j.biotechadv.2015.04,008.

[121] J. Shi, R.N. Johnson, J.G. Schellinger, P.M. Carlson, S.H. Pun, Reducible HPMA-cooligolysine copolymers for nucleic acid delivery, Int. J. Pharm. 427 (2012) 113-122.

[122] L. Wang, J. Kristensen, D.E. Ruffner, Delivery of antisense oligonucleotides using HPMA polymer: synthesis of a thiol polymer and its conjugation to water-soluble molecules, Bioconjugate Chem. 9 (1998) 749-757.

[123] A. Gaowa, T. Horibe, M. Kohno, Y. Tabata, H. Harada, M. Hiraoka, K. Kawakami, Enhancement of anti-tumor activity of hybrid peptide in conjugation with carboxymethyl dextran via disulfide linkers, Eur. J. Pharm. Biopharm. 92 (2015) 228-236.

[124] Y. Reiter, R.J. Kreitman, U. Brinkmann, I. Pastan, Cytotoxic and antitumor activity of a recombinant immunotoxin composed of disulfide-stabilized anti-Tac Fv fragment and truncated Pseudomonas exotoxin, Int. J. Cancer 58 (1994) 142-149.

[125] L.M. Hinman, P.R. Hamann, R. Wallace, A.T. Menendez, F.E. Durr, J. Upeslacis, Preparation and characterization of monoclonal antibody conjugates of the calicheamicins: a novel and potent family of antitumor antibiotics, Cancer Res. 53 (1993) 3336-3342.

[126] V. Cuchelkar, P. Kopečková, J. Kopeček, Synthesis and biological evaluation of disulfidelinked HPMA copolymer-mesochlorin e 6 conjugates, Macromol. Biosci. 8 (2008) 375-383.

[127] B. Yameen, C. Vilos, W.I. Choi, A. Whyte, J. Huang, L. Pollit, O.C. Farokhzad, Drug delivery nanocarriers from a fully degradable PEG-conjugated polyester with a reductionresponsive backbone, Chemistry 21 (2015) 11325-11329.

[128] J.A. Wolf, D.B. Rozema, Breaking the bonds: Non-viral vectors become chemically dynamic, Mol. Therapy 16 (2008) 8-15.

[129] B.B. Lundy, A. Convertine, M. Miteva, P.S. Stayton, Neutral polymeric micelles for RNA delivery, Bioconjugate Chem. 24 (2013) 398-407.

[130] P.L. Carl, P.K. Chakravarty, J.A. Katzellenbogen, A novel connector linkage applicable in prodrug design, J. Med. Chem. 24 (1981) 479-480.

[131] A. Alouane, R. Labruère, T. Le Saux, F. Schmidt, L. Jullien, Self-immolative spacers: Kinetic aspects, structure-property relationships, and applications, Angew. Chem. Int. Ed. 54 (2015) 7492-7509.

[132] A. Warnecke, Site-specific prodrug activation and the concept of self-immolation, in: $F$. Kratz, P. Senter, H. Steinhagen (Eds.), Drug Delivery in Oncology, Vol. 2, Wiley-VCH, Weinheim, Germany, 2012, pp. 553-589.

[133] F.M. de Groot, W.J. Loos, R. Koekkoek, L.W. van Berkom, G.F. Busscher, A.E. Seelen, C. Albrecht, P. de Bruijn, H.W. Scheeren, Elongated multiple electronic cascade and cyclization spacer systems in activatible anticancer prodrugs for enhanced drug release, J. Org. Chem. 66 (2001) 8815-8830.

[134] I. Schechter, A. Berger, On the size of the active site in proteases. I. Papain, Biochem. Biophys. Res. Commun. 27 (1967) 157-162.

[135] S. Gao, Z. Lu, B. Petri, P. Kopečková, J. Kopeček, Colon-specific 9-aminocamptothecinHPMA copolymer conjugates containing a 1,6-elimination spacer, J. Controlled Release 110 (2006) 323-331. 
[136] S. Gao, Z. Lu, P. Kopečková, J. Kopeček, Biodistribution and pharmacokinetics of colonspecific HPMA copolymer - 9-aminocamptothecin conjugate in mice, J. Controlled Release 117 (2007) 179-185.

[137] D. Putnam, J. Kopeček, Enantioselective release of 5-fluorouracil from N-(2hydroxypropyl)methacrylamide-based copolymers via lysosomal enzymes, Bioconjugate Chem. 6 (1995) 483-492.

[138] A. Sagi, R. Weinstain, N. Karton, D. Shabat, Self-immolative polymers, J. Am. Chem. Soc. 130 (2008) 5434-5435.

[139] A. Sagi, E. Segal, R. Satchi-Fainaro, D. Shabat, Remarkable drug-release enhancement with an elimination-based AB3 self-immolative dendritic amplifier, Bioorg. Med. Chem. 15 (2007) 3720-3727.

[140] H. Ding, S. Inoue, A.V. Ljubimov, R. Patil, J. Portilla-Arias, J. Hu, B. Konda, K.A. Wawrowsky, M. Fujita, N. Karabalin, T. Sasaki, K.L. Black, E. Holler, J.Y. Ljubimova, Inhibition of brain tumor growth by intravenous poly(b-L-malic acid) nanobioconjugate with pH-dependent drug release, Proc. Natl. Acad. Sci. USA 107 (2010) 18143-18148.

[141] G.Y. Berguig, A.J. Convertine, J. Shi, M.C. Palanca-Wessels, C.L. Duvall. S.H. Pun, O.W. Press, P.S. Stayton, Intracellular delivery and trafficking dynamics of a lymphomatargeting antibody-polymer conjugate, Mol. Pharmaceutics 9 (2012) 3506-3514.

[142] B. Říhová, J. Kopeček, Biological properties of targetable poly[N-(2hydroxypropyl)methacrylamide] - antibody conjugates, J. Controlled Release 2 (1985) 1324.

[143] K.D. Fowers, J. Kopeček, Targeting of multidrug-resistant human ovarian carcinoma cells with anti-P-glycoprotein antibody conjugates, Macromol. Biosci. 12 (2012) 502-514.

[144] T. Merdan, J. Callahan, H. Petersen, K. Kunath, U. Bakowsky, P. Kopečková, T. Kissel, J. Kopeček, Pegylated polyethylenimine - Fab' antibody fragment conjugates for targeted gene delivery to human ovarian carcinoma cells, Bioconjugate Chem. 14 (2003) 989-996.

[145] Z.-R. Lu, P. Kopečková, J. Kopeček, Polymerizable Fab' antibody fragments for targeting of anticancer drugs, Nature Biotechnol. 17 (1999) 1101-1104.

[146] R. Duncan, L.C.W. Seymour, L. Scarlett, J.B. Lloyd, P. Rejmanová, J. Kopeček, Fate of $\mathrm{N}$-(2-hydroxypropyl)methacrylamide copolymers with pendent galactosamine residues after intravenous administration to rats, Biochim. Biophys. Acta 880 (1986) 62-71.

[147] A. David, P. Kopečková, A. Rubinstein, J. Kopeček, Enhanced biorecognition and internalization of HPMA copolymers containing multi- or multivalent carbohydrate sidechains by human hepatocarcinoma cells, Bioconjugate Chem. 12 (2001) 890-899.

[148] G. Journo-Gershfeld, D. Kapp, Y. Shamay, J. Kopeček, A. David, Hyaluronan oligomersHPMA copolymer conjugates for targeting paclitaxel to CD44-overexpressing ovarian carcinoma, Pharmaceutical Res. 29 (2012) 1121-1133.

[149] S. Wróblewski, M. Berenson, P. Kopečková, J. Kopeček, Biorecognition of HPMA copolymer-lectin conjugates as an indicator of differentiation of cell-surface glycoproteins in development, maturation and diseases of human and rodent gastrointestinal tissues, J. Biomed. Mater. Res. 51 (2000) 329-342.

[150] S. Wróblewski, B. Říhová, P. Rossmann, T. Hudcovicz, Z. Řeháková, P. Kopečková, J. Kopeček, The influence of a colonic microbiota on HPMA copolymer - lectin conjugates binding in rodent intestine, J. Drug Targeting 9 (2001) 85-94.

[151] O.H. Aina, J. Marik, R. Liu, D.H. Lau, K.S. Lam, Identification of novel targeting peptides for human ovarian cancer cells using "one-bead-one-compound" combinatotial libraries, Mol. Cancer Ther. 4 (2005) 806-813.

[152] A. Tang, P. Kopečková, J. Kopeček, Binding and cytotoxicity of HPMA copolymer conjugates to lymphocytes mediated by receptor-binding epitopes, Pharmaceutical Res. 20 (2003) 360-367.

[153] Y. Shamay, D. Paulin, G. Ashkenazy, A. David, E-selectin binding peptide-drugconjugates and their selective cytotoxicity against vascular endothelial cells, Biomaterials 30 (2009) 6460-6468. 
[154] Y. Shamay, L. Raviv, M. Golan, E. Voronov, R.N. Apte, A. David, Inhibition of primary and metastatic tumors in mice by E-selectin-targeted polymer-drug conjugates, J. Controlled Release (2015) doi: 10.1016/j.jconrel.2015.08.029.

[155] B. Buckway, Y. Wang, A. Ray, H. Ghandehari, Overcoming the stromal barrier for targeted delivery of HPMA copolymers to pancreatic tumors, Int. J. Pharm. 456 (2013) 202-211.

[156] K. Greish, A. Ray, H. Bauer, N. Larson, A. Malugin, D. Pike, M. Haider, H. Ghandehari, Anticancer and antiangiogenic activity of HPMA copolymer-aminohexylgeldanamycinRGDfK conjugates for prostate cancer therapy, J. Controlled Release 151 (2011) 263270.

[157] E. Levy-Nissenbaum, A.F. Radovic-Moreno, A.Z. Wang, R. Langer, O.C. Farokhzad, Nanotechnology and aptamers: application in drug delivery, Trends Biotechnol. 26 (2008) 442-449.

[158] J. Kopeček, Polymer - drug conjugates: Origins, progress to date and future directions, Adv. Drug Delivery Rev. 65 (2013) 49-59.

[159] T.M. Allen, Ligand-targeted therapeutics in anticancer therapy, Nature Rev. Cancer 2 (2002) 750-763.

[160] Y. Zhou, J. Kopeček, Biological rationale for the design of polymeric anti-cancer nanomedicines, J. Drug Targeting 21 (2012) 1-26.

[161] A. Dubrovska, J. Elliott, R.J. Salamone, S. Kim, L.J. Aimone, J.R. Walker, J. Watson, M. Sauveur-Michel, C. Garcia-Echeverria, C.Y. Cho, V.A. Reddy, P.G. Schultz, Combination therapy targeting both tumor-initiating and differentiated cell populations in prostate carcinoma, Clin. Cancer Res. 16 (2010) 5692-5702.

[162] Y. Zhou, J. Yang, J. Kopeček, Selective inhibitory effect of HPMA copolymer-cyclopamine conjugate on prostate cancer stem cells, Biomaterials 33 (2012) 1863-1872.

[163] Y. Zhou, J. Yang, J.S. Rhim, J. Kopeček, HPMA copolymer-based combination therapy toxic to both prostate cancer stem/progenitor cells and differentiated cells induces durable anti-tumor effects, J. Control. Release 172 (2013) 946-953.

[164] R. Duncan, F. Spreafico, Polymer conjugates. Pharmacokinetic considerations for design and development, Clin. Pharmacokinet. 27 (1994) 290-306.

[165] N. Bertrand, J.-C. Leroux, The journey of a drug-carrier in the body: An anatomophysiological perspective, J. Controlled Release 161 (2012) 152-163.

[166] R. Zhang, J. Yang, M. Sima, Y. Zhou, J. Kopeček, Sequential combination therapy of ovarian cancer with degradable $N$-(2-hydroxypropyl)methacrylamide copolymer paclitaxel and gemcitabine conjugates, Proc. Natl. Acad. Sci. USA 111 (2014) 12181-12186.

[167] T. Minko, L. Rodriguez-Rodriguez, V. Pozharov, Nanotechnology approaches for personalized treatment of multidrug resistant cancers, Adv. Drug Deliv. Rev. 65 (2013) 1880-1895.

[168] S.G. Aller, J. Yu, A. Ward, S. Chittaboina, R. Zhuo, P.M. Harrell, Y.T. Trinh, Q. Zhang, I.L. Urbatsch, G. Chang, Structure of P-glycoprotein reveals a molecular basis for polyspecific drug binding, Science 323 (2009) 1718-1722.

[169] T. Minko, P. Kopečková, J. Kopeček, Comparison of the anticancer effect of free and HPMA copolymer-bound adriamycin in human ovarian carcinoma cells, Pharmaceutical Res. 16 (1999) 986-996.

[170] T. Minko, P. Kopečková, J. Kopeček, Chronic exposure to HPMA copolymer-bound adriamycin does not induce multidrug resistance in a human ovarian carcinoma cell line, J. Controlled Release 59 (1999) 133-148.

[171] T. Minko, HPMA copolymers for modulating cellular signaling and overcoming multidrug resistance, Adv. Drug Deliv. Rev. 62 (2010) 192-202.

[172] J. Couzin-Frankel, Cancer immunotherapy, Science 342 (2013) 1432-1433.

[173] B. Říhová, P. Kopečková, J. Strohalm, P. Rossmann, V. Větvička, J. Kopeček, Antibody directed affinity therapy applied to the immune system: In vivo effectiveness and limited 
toxicity of daunomycin conjugates to HPMA copolymers and targeting antibody, Clin. Immunol. Immunopathol. 46 (1988) 100-114.

[174] B. Říhová, J. Strohalm, K. Hoste, M. Jelínková, O. Hovorka, M. Kovář, D. Plocová, M. Šírová, M. Štastný, E. Schacht, K. Ulbrich, Immunoprotective therapy with targeted anticancer drugs, Macromol. Symp. 172 (2001) 21-28.

[175] B. Ríhová, L. Kovář, M. Kovář, O. Hovorka, Cytotoxicity and immunostimulation: double attack on cancer cells with polymer therapeutics, Trend Biotechnol. 27 (2009) 11-17.

[176] B. Ríhová, M. Kovář, Immunogenicity and immunomodulatory properties of HPMA-based polymers, Adv. Drug Deliv. Rev. 62 (2010) 184-191.

[177] M. Šírová, J. Strohalm, V. Šubr, D. Plocová, P. Rossmann, T. Mrkvan, K. Ulbrich, B. Ríhová, Treatment with HPMA copolymer-based doxorubicin conjugate containing human immunoglobulin induces long-lasting systemic anti-tumor immunity in mice, Cancer Immunol. Immunother. 56 (2007) 35-47.

[178] R. Duncan, M.J. Vicent, Polymer therapeutics - prospects for $21^{\text {st }}$ century: The end of the beginning, Adv. Drug Delivery Rev. 65 (2013) 60-70.

[179] R. Duncan, Polymer therapeutics: Top 10 selling pharmaceuticals - what next? J. Controlled Release 190 (2014) 371-380.

[180] B.S. Tucker, B.S. Summerlin, Poly(N-(2-hydroxypropyl)methacrylamide) - based nanotherapeutics, Polym. Chem. 5 (2014) 1566-1572.

[181] J.M. Hartley, J. Kopeček, Smart polymer-based nanomaterials, in: V.P. Torchilin (Ed.), Smart Pharmaceutical Nanocarriers, Imperial College Press, London (2015) in press.

[182] J. Yang, J. Kopeček, Polymer therapeutics, J. Controlled Release 190 (2014) 288-303.

[183] C. Li, S. Wallace, Polymer-drug conjugates: Recent development in clinical oncology, Adv. Drug Deliv. Rev. 60 (2008) 886-898.

[184] D.P. Nowotnik, E. Cvitkovic, ProLindac (AP5346): A review of the development of an HPMA DACH platinum polymer therapeutic, Adv. Drug Deliv. Rev. 61 (2009) 1214-1219.

[185] R. Duncan, Development of HPMA copolymer-anticancer conjugates: clinical experience and lessons learnt, Adv. Drug Deliv. Rev. 61 (2009) 1131-1148.

[186] L. Paz-Ares, H. Ross, M. O'Brien, A. Riviere, U. Gatzemeier, J. Von Pawel, E. Kaukel, L. Freitag, W. Digel, H. Bischoff, R. García-Campelo, N. lannotti, P. Reiterer, I. Bover, J. Prendiville, A.J. Eisenfeld, F.B. Oldham, B. Bandstra, J.W. Singer, P. Bonomi, Phase III trial comparing paclitaxel poliglumex vs docetaxel in the second-line treatment of nonsmall-cell lung cancer, Br. J. Cancer 98 (2008) 1608-1613.

[187] V.J. Venditto, F.C. Szoka, Jr., Cancer nanomedicines: so many papers and so few drugs! Adv. Drug Deliv. Rev. 65 (2013) 80-88.

[188] J. Yang, K. Luo, H. Pan, P. Kopečková, J. Kopeček, Synthesis of biodegradable multiblock copolymers by click coupling of RAFT-generated heterotelechelic polyHPMA conjugates, Reactive Functional Polym. 71 (2011) 294-302.

[189] K. Luo, J. Yang, P. Kopečková, J. Kopeček, Biodegradable multiblock N-(2hydroxypropyl)methacrylamide copolymers via reversible addition-fragmentation chain transfer polymerization and click chemistry, Macromolecules 44 (2011) 2481-2488.

[190] H. Pan, J. Yang, P. Kopečková, J. Kopeček, Backbone degradable multiblock N-(2hydroxypropyl)methacrylamide copolymer conjugates via reversible additionfragmentation chain transfer polymerization and thiol-ene coupling reaction, Biomacromolecules 12 (2011) 247-252.

[191] R. Zhang, K. Luo, J. Yang, M. Sima, Y. Sun, M.M. Janát-Amsbury, J. Kopeček, Synthesis and evaluation of a backbone biodegradable multiblock HPMA copolymer nanocarrier for the systemic delivery of paclitaxel, J. Control. Release 166 (2013) 66-74.

[192] N. Larson, J. Yang, A. Ray, D.L. Cheney, H. Ghandehari, J. Kopeček, Biodegradable multiblock poly( $N$-2-hydroxypropyl)methacrylamide gemcitabine and paclitaxel conjugates for ovarian cancer cell combination treatment, Int. J. Pharm. 454 (2013) 435-443.

[193] H. Pan, M. Sima, J. Yang, J. Kopeček, Synthesis of long-circulating, backbone degradable HPMA copolymer-doxorubicin conjugates and evaluation of molecularweight-dependent antitumor efficacy, Macromol. Biosci. 13 (2013) 155-160. 
[194] J. Yang, J. Kopeček, Recent developments and preclinical evaluation of HPMA copolymer-drug conjugates as anticancer therapeutics, 40 ${ }^{\text {th }}$ Annual Meeting of the Controlled Release Society, Hawaii Convention Center, Honolulu, Hawaii, July 21-24, 2013.

[195] H. Pan, M. Sima, S.C. Miller, P. Kopečková, J. Yang, J. Kopeček, Efficiency of high molecular weight backbone degradable HPMA copolymer-prostaglandin E1 conjugate in promotion of bone formation in overiectomized rats, Biomaterials 34 (2013) 6528-6538.

[196] J.P. Deans, H. Li, M.J. Polyak, CD20-mediated apoptosis: signaling through lipid rafts, Immunology 107 (2002) 176-182.

[197] J. Yang, C. Xu, C. Wang, J. Kopeček, Refolding hydrogels self-assembled from HPMA graft copolymers by antiparallel coiled-coil formation, Biomacromolecules 7 (2006) 11871195.

[198] J. Yang, K. Wu, Č. Koňák, J. Kopeček, Dynamic light scattering study of the selfassembly of HPMA hybrid graft copolymers, Biomacromolecules 9 (2008) 510-517.

[199] J. Kopeček, J. Yang, Smart self-assembled hybrid hydrogel biomaterials, Angew. Chem. Int. Ed. 51 (2012) 7396-7417.

[200] T.-W. Chu, J. Kopeček, Drug-free macromolecular therapeutics - a new paradigm in polymeric nanomedicines, Biomater. Sci. 3 (2015) 908-922.

[201] K.C. Anderson, M.P. Bates, B.L. Slaughenhoupt, G.S. Pinkus, S.F. Schlossman, L.M. Nadler, Expression of human B cell-associated antigens on leukemias and lymphomas: a model of human B cell differentiation, Blood 63 (1984) 1424-1433.

[202] R.B. Michel, M.J. Mattes, Intracellular accumulation of the anti-CD20 antibody 1 F5 in Blymphoma cells, Clin. Cancer Res. 8 (2002) 2701-2713.

[203] T.F. Tedder, P. Engel, CD20: a regulator of cell-cycle progression of B lymphocytes, Immunol. Today 15 (1994) 450-454.

[204] A.D. Zelenetz, and 33 others; National comprehensive cancer network, Non-Hodgkin's lymphomas, version 4.2014, J. Natl. Compr. Cancer Netw. 12 (2014) 1282-1303.

[205] P. Stashenko, L.M. Nadler, R. Hardy, S.F. Schlossman, Characterization of a human B lymphocyte-specific antigen, J. Immunol. 125 (1980) 1678-1685.

[206] D.G. Maloney, Anti-CD20 antibody therapy for B-cell lymphomas, N. Engl. J. Med. 366 (2012) 2008-2016.

[207] D. Shan, J.A. Ledbetter, O.W. Press, Apoptosis of malignant human B cells by ligation of CD20 with monoclonal antibodies, Blood 91 (1998) 1644-1652.

[208] P. Boross, J.H.W. Leusen, Mechanisms of action of CD20 antibodies, Am. J. Cancer Res. 2 (2012) 676-690.

[209] M. Okroj, A. Österborg, A.M. Blom, Effector mechanisms of anti-CD20 monoclonal antibodies in B cell malignancies, Cancer Treat. Rev. 39 (2013) 632-639.

[210] M.A. Ghetie, H. Bright, E.S. Vitetta, Homodimers but not monomers of Rituxan (chimeric anti-CD20) induce apoptosis in human B-lymphoma cells and synergize with a chemotherapeutic agent and an immunotoxin. Blood 97(5), 1392-1398 (2001).

[211] N. Zhang, L.A. Khawli, P. Hu, A.L. Epstein, Generation of rituximab polymer may cause hyper-cross-linking-induced apoptosis in non-Hodgkin's lymphomas. Clin. Cancer Res. 11(16), 5971-5980 (2005).

[212] R.N. Johnson, P. Kopečková, J. Kopeček, Synthesis and evaluation of multivalent branched HPMA copolymer-Fab' conjugates targeted to the B-cell antigen CD20. Bioconjug. Chem. 20(1), 129-137 (2009).

[213] R.N. Johnson, P. Kopečková, J. Kopeček, Biological activity of anti-CD20 multivalent HPMA copolymer-Fab' conjugates, Biomacromolecules 13, 727-735 (2012)

[214] T.-W. Chu, J. Yang, J. Kopeček, Anti-CD20 multivalent HPMA copolymer-Fab' conjugates for the direct induction of apoptosis, Biomaterials 33, 7174-7181 (2012).

[215] J. Popov, A.I. Kapanen, C. Turner, R. Ng, C. Tucker, G. Chiu, M.B. Bally, G. Chikh, Multivalent rituximab lipid nanoparticles as improved lymphoma therapies: indirect mechanism of action and in vivo activity, Nanomedicine 6 (2011) 1575-1591. 
[216] S.R. Aluri, P. Shi, J.A. Gustafson, W. Wang, Y-A. Lin, H. Cui, S. Liu, P.S. Conti, Z. Li, P. Hu, A.L. Epstein, J.A. MacKay, A hybrid protein-polymer nanoworm potentiates apoptosis better than a monoclonal antibody, ACS Nano 8 (2014) 2064-2076.

[217] D.A. Goodwin, C.F. Meares, Advances in pretargeting biotechnology, Biotechnol. Adv. 19 (2001) 435-450.

[218] L.C. Lands, New therapies, new concerns: rituximab-associated lung injury. Pediatr. Nephrol. 25 (2010) 1001-1003.

[219] Y.B. Yu, Coiled coils: stability, specificity, and drug delivery potential, Adv. Drug Deliv. Rev. 54 (2002) 1113-1129.

[220] K. Wu, J. Liu, R.N. Johnson, J. Yang, J. Kopeček, Drug-free macromolecular therapeutics: Induction of apoptosis by coiled-coil-mediated cross-linking of antigens on the cell surface, Angew. Chem. Int. Ed. 49 (2010) 1451-1455.

[221] K.G. Wu, J. Yang, J. Liu, J., Kopeček, Coiled-coil based drug-free macromolecular therapeutics: In vivo efficacy, J. Control. Release 157 (2012) 126-131.

[222] J.M. Hartley, T.-W. Chu, E.M. Peterson, R. Zhang, J. Yang, J. Harris, J. Kopeček, SuperResolution imaging and quatitative analysis of membrane protein/lipid raft clustering mediated by cell surface self-assembly of hybrid nanoconjugates, ChemBioChem, (2015) doi: 10.1002/cbic.201500278

[223] K. S. George, S. Wu, Lipid raft: A floating island of death or survival, Toxicol. Appl. Pharmacol. 259 (2012) 311-319.

[224] I. Semac, C. Palomba, K. Kulangara, N. Klages, G. van Echten-Deckert, B. Borisch, D.C. Hoessli, Anti-CD20 therapeutic antibody rituximab modifies the functional organization of rafts/microdomains of B lymphoma cells, Cancer Res. 63 (2003), 534-540.

[225] A. Ivanov, S.A. Beers, C.A. Walshe, J. Honeychurch, W. Alduaij, K.L. Cox, K.N. Potter, S. Murray, C.H.T. Chan, T. Klymenko, J. Erenpreisa, M.J. Glennie, T.M. Illidge, M.S. Cragg, Monoclonal antibodies directed to CD20 and HLA-DR can elicit homotypic adhesion followed by lysosome-mediated cell death in human lymphoma and leukemia cells, J. Clin. Invest. 119 (2009) 2143-2159.

[226] R. Zhang, J. Yang, T.-W. Chu, J.M. Hartley, J. Kopeček, Multimodality imaging of coiledcoil mediated self-assembly in a "drug-free" therapeutic system, Adv. Healthcare Mat. 4 (2015) 1054-1065.

[227] M. Kverka, J.M. Hartley, T.-W. Chu, J. Yang, R. Heidchen, J. Kopeček, Immunogenicity of coiled-coil based drug-free macromolecular therapeutics, Biomaterials 35 (2014) 58865896.

[228] B. Ríhová, J. Kopeček, K. Ulbrich, V. Chytrý, Immunogenicity of N-(2hydroxypropyl)methacrylamide copolymers, Makromol Chem. Suppl 9 (1985) 13-24.

[229] B. Ŕíhová, Biocompatibility of biomaterials: Hemocompatibility, immunocompatiblity and biocompatibility of solid polymeric materials and soluble targetable polymeric carriers, Adv. Drug Deliv. Rev. 21 (1996) 157-176.

[230] O.W. Press, F. Appelbaum, J.A. Ledbetter, P.J. Martin, J. Zarling, P. Kidd, E.D. Thomas, Monoclonal antibody 1F5 (anti-CD20) serotherapy of human B cell lymphomas, Blood 69 (1987) 584-591.

[231] T.A. Johnson, O.W. Press, Therapy of B-cell lymphomas with monoclonal antibodies and radioimmunoconjugates: the Seattle experience, Ann. Hematol. 79 (2000) 175-182.

[232] T.-W. Chu, J. Yang, R. Zhang, M. Sima, J. Kopeček, Cell surface self-assembly of hybrid nanoconjugates via oligonucleotide hybridization induces apoptosis, ACS Nano 8 (2014) 719-730.

[233] L.K. Boerner, Nanoconjugates trigger cell suicide. Chem. Eng. News, January 7, 2014; http://cen.acs.org/articles/92/web/2014/01/Nanoconjugates-Trigger-Cancer-CellSuicide.html

[234] N.C. Seeman, DNA in a material world, Nature 421 (2003) 427-431.

[235] S. Nagahara, T. Matsuda, Hydrogel formation via hybridization of oligonucleotides derivatized in water-soluble vinyl polymers, Polym. Gels Netw. 4 (1996) 111-127. 
[236] J. Li, C. Fan, H. Pei, J. Shi, Q. Huang, Smart drug delivery nanocarriers with selfassembled DNA nanostructures, Adv. Mater. 25 (2013) 4386-4396.

[237] P. E. Nielsen, DNA analogues with nonphosphodiester backbones, Annu. Rev. Biophys. Biomol. Struct. 24 (1995) 167-183.

[238] J. Summerton, D. Weller, Morpholino antisense oligomers: design, preparation, and properties, Antisense Nucleic Acid Drug Dev. 7 (1997) 187-195.

[239] J.E. Summerton, Morpholino, siRNA, and S-DNA compared: impact of structure and mechanism of action on off-target effects and sequence specificity, Curr. Top. Med. Chem. 7 (2007) 651-660.

[240] A. Amantana, P.L. Iversen, Pharmacokinetics and biodistribution of phosphorodiamidate morpholino antisense oligomers, Curr. Opin. Pharmacol. 5 (2005) 550-555.

[241] T.-W. Chu, R. Zhang, J. Yang, M.P. Chao, P.J. Shami, J. Kopeček, A two-step pretargeted nanotherapy for CD20 crosslinking may achieve superior anti-lymphoma efficacy to rituximab, Theranostics 5 (2015) 834-846.

[242] T.-W. Chu, K.M. Kosak, P.J. Shami, J. Kopeček, Drug-free macromolecular therapeutics induce apoptosis of patient chronic lymphocytic leukemia cells, Drug Deliv. Translational Res. 4 (2014) 389-394.

[243] A. Molina, A decade of rituximab: improving survival outcomes in non-Hodgkin's lymphoma, Annu. Rev. Med. 59 (2008) 237-250.

[244] R. Weissleder, M.J. Pittet, Imaging in the era of molecular oncology, Nature 452 (2008) 580-589.

[245] A. Srivatsan, X. Chen, Recent advances in nanoparticle-based nuclear imaging of cancers, Adv. Cancer Res. 124 (2014) 83-129.

[246] V. Hamaguchi, Y. Xiu, K. Komura, F. Nimmerjahn, T.T. Tedder, Antibody isotype-specific engagement of Fcg receptors regulates B lymphocyte depletion during CD20 immunotherapy, J. Exp. Med. 203 (2006) 743-753.

[247] J.C. Edwards, C. Cambridge, Sustained improvement in rheumatoid arthritis following a protocol designed to deplete B lymphocytes, Rheumatology 40 (2001) 205-211.

[248] G.J. Silverman, S. Weisman, Rituximab therapy and autoimmune disorders: prospects for anti-B cell therapy, Artritis Rheum. 48 (2003) 1484-1492.

[249] S.L. Hauser, E. Waubant, D.L. Arnold, T. Vollmer, J. Antel, R.J. Fox, A. Bar-Or, M. Panzara, N. Sarkar, S. Agarwal, A. Langer-Gould, C.H. Smith, HERMES Trial Group, Bcell depletion with rituximab in relapsing-remitting multiple sclerosis, N. Engl. J. Med. 358 (2008) 676-688. 